Article

\title{
Feasibility Assessment of a Water Supply Reliability Index for Water Resources Project Planning and Evaluation
}

\author{
Boris Po-Tsang Chen ${ }^{1, * \mathbb{1} \text { and } \text { Chang-Shian Chen }}{ }^{2}$ \\ 1 Construction and Disaster Prevention Research Center, Feng Chia University, No. 100 Wenhwa Rd., Seatwen, \\ Taichung 40724, Taiwan \\ 2 Department of Water Resources Engineering, Feng Chia University, No. 100 Wenhwa Rd., Seatwen, \\ Taichung 40724, Taiwan; cschen@fcu.edu.tw \\ * Correspondence: btchen@mail.fcu.edu.tw; Tel.: +886-4-24517250 (ext. 3170); Fax: +886-4-24525960
}

Received: 27 August 2019; Accepted: 19 September 2019; Published: 23 September 2019

\begin{abstract}
In order to estimate water supply potential, the effects of shortages on water users, and the uncertainty of local headspring conditions during the planning stage of reservoir construction, the Shortage Index (SI) is often employed. However, the criterion used in the SI is difficult to adjust to satisfy local conditions and objectives. The SI also employs an ambiguous definition of value. Thus, this study adopted a water supply reliability index (WSRI) as an alternative to the SI for providing the criterion for water resources project planning. The value of the WSRI is easily understood, because it is defined according to the real water supply situation and it has a strong linear relationship with values of SI. For any given water supply system, the estimated results derived from this study could serve as an additional remark on different SI values to explain the relevant water supply considerations. In addition, for a new planning site, the estimated results of this study could provide another way for engineers to evaluate the maximum water supply capability. Consequently, an interesting avenue of investigation in future research would be the incorporation of the WSRI with the risk of deficit frequency in establishing an efficient and transparent bottom-up approach for water resources management, involving all the relevant stakeholders.
\end{abstract}

Keywords: Generalized Shortage Index (GSI); Shortage Index (SI); water supply planning; water supply potential; reliability index

\section{Introduction}

Global warming and climate change concerns have been growing over the last decade [1-3]. Dai et al. [4] have noted that the available runoff is reducing in most parts of the world. Extreme climate conditions in conjunction with a growing population and economic development are straining water resources around the world [5,6], and there is a general awareness that water crises are management crises. As a result, finding methods to exploit and allocate water resources more effectively has become a serious and urgent issue [7]. The effective allocation of available water is necessary for water resource development and utilization. For the reasons mentioned above, the basic natural circumstances (such as hydrological and physiographical conditions) and the operational potential of existing hydrological facilities (such as joint operation, extension and further exploitation) must be integrated for efficient water resource management.

In Taiwan, the total water demand is met by $48.27 \%$ from streamflow diversion, $20.57 \%$ from reservoir releases, and 31.16\% from groundwater [8]. The government in Taiwan has to face two problems regarding water resource management. The first is climate change, which is partly considered as reducing the amount of rainfall during the dry season and increasing it during the wet season. 
Consequently, the streamflow diversion available is decreasing during the dry season, while torrential rainfall results in soil erosion and soil creep in reservoir catchment areas, accelerating sedimentation and reducing the operational life of reservoirs. For an example, in 2009, Typhoon Morakot reduced the capacity of the Tsengweng and Nanhua reservoirs by around $100 \times 10^{6}$. and $52 \times 10^{6} \mathrm{~m}^{3}$, respectively [9]. The second major problem is land subsidence due to the over pumping of groundwater [10]. Therefore, the related government departments decided to gradually revoke the water rights given in relation to groundwater, and to make up for water deficit with surface water supply systems [11]. These two problems highlight the importance of reservoir regulation in Taiwan. For this reason, although there are many methods, both engineered and non-engineered, could improve the exploitation and utilization of water resources. The engineered methods are, for example, weir building, reservoir creation, transbasin diversion, ground water dam building, and artificial lake creation, and the non-engineered ones, are like sea water conversion, water reuse, waste water reuse, reservoir silting removing and prevention, regional water allocation, agricultural water transfer, and soil and water conservation.

However, all water resource policies tend to cause disagreement among stakeholders. With regard to the public who use the water supply, it is difficult for water management officials to explain any water shortages or the potentially more severe crises that the water supply may face in the future. In general, the important details of water shortage events that engineers need to consider include the duration, quantity, and frequency. More specifically, any account of a water shortage has to consider the duration and quantity of the shortage using a short-term index, as well as the frequency in a long-term index. The short-term index is not sufficient to explain the potential risk to the long-term water supply, and the long-term index needs significant, professional knowledge to develop and be understood. These facts can lead to misunderstandings and disputes between the official department and the public with regard to water supply policy. For example, if the official department uses the shortage index (SI) to explain the design of the water supply system, in conjunction with other short-term indexes, then during water shortages the public may ask why the SI value was not set higher before the shortage, as is possible in other water supply systems. There was a real example of this in Taiwan in 2003. Even though the engineers knew that a lower SI was better, it was difficult to make the public understand this, and this led to numerous complaints. Moreover, many countries now accept that establishing efficient and transparent bottom-up approaches to water management and involving all stakeholders in the issue of water resource development are important but challenging aims for the future [12]. For this reason, a good water supply/shortage index which could act as the communication bridge between officials and the public is required.

Therefore, the major purpose of this study is two-fold: the first is investigating the yield of water supply reservoirs under the uncertainty of available reservoir inflow in different hydrological conditions, and the second is to explore the relationship between the values of the water supply reliability index (WSRI) thus developed and the currently used shortage index. Based on the outcome of this, this work then offers several suggestions for better water supply planning. The article concludes with implications for theory, research, and practice. While research on these questions is still at an early stage, the findings will have broad implications in a number of areas, and could specifically serve as the basis for a further study of water supply system planning.

\section{Methodology}

\subsection{Common Measurements for Water Supply Evaluation and Planning}

A suitable indicator or standard is required for water supply planning. Water shortages are judged on three factors during the reservoir water resource process: duration, magnitude (shown in Figure 1), and frequency [13]. The first two factors are usually integrated as the consideration of shortage intensity (i.e., the ratio of the shortage magnitude to the shortage duration), and the shortage frequency is considered as a combination of the intensity and its incidence to describe the 
long-term performance of a particular water supply system. Several common indexes used to evaluate deficiencies during the water supply process are described below, and they are compared in Table 1.

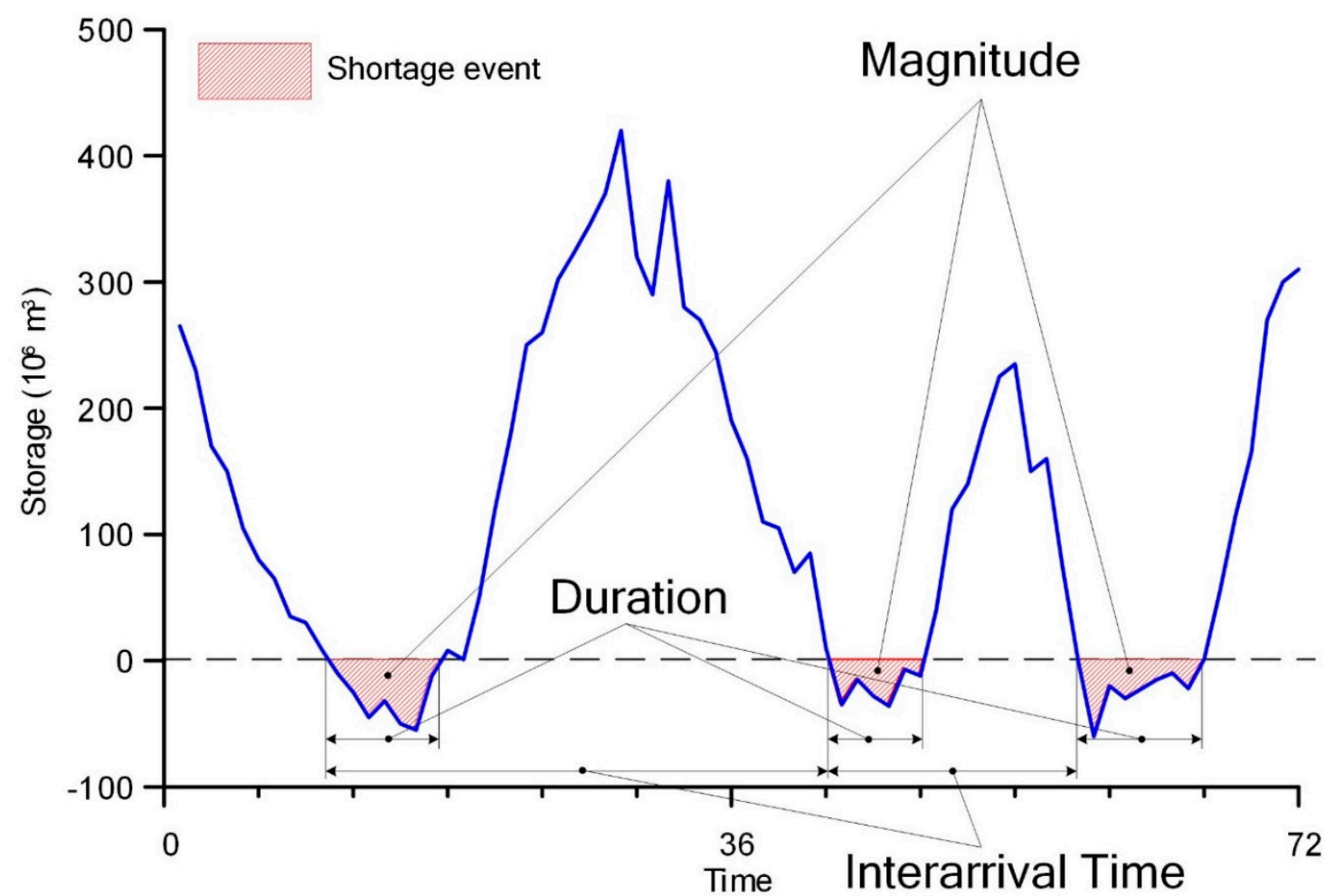

Figure 1. Definition sketch of water shortage characteristics of reservoir water supply process.

Table 1. The comparison of four common water shortage evaluation indexes.

\begin{tabular}{|c|c|c|}
\hline Name & & Remarks \\
\hline $\begin{array}{c}\text { Water-use index, WI } \\
{[14,15]} \\
\frac{W_{S}}{W_{D}}\end{array}$ & $\begin{array}{l}\text { Usage } \\
\text { Advantages } \\
\text { Shortcomings }\end{array}$ & $\begin{array}{l}\text { The WI is used to understand the actual water supply situation during a } \\
\text { specific (short-term) period to operate water supply regulation or planning. } \\
\text { Calculation is simple and easy to understand. } \\
\text { It cannot consider the frequency of water shortages. Therefore, it is not suitable } \\
\text { for the economic consideration of long-term water resources planning }\end{array}$ \\
\hline $\begin{array}{c}\text { Shortage index, SI } \\
\text { [16] } \\
\frac{100}{N} \sum_{t=1}^{N}\left(\frac{A S_{t}}{A D_{t}}\right)^{2}\end{array}$ & $\begin{array}{l}\text { Usage } \\
\text { Advantages } \\
\text { Shortcomings }\end{array}$ & $\begin{array}{l}\text { The SI is applied to evaluate the relative water shortage situation with given } \\
\text { schemes of water supply system design during the simulation period } \\
\text { (long-term period) for professional engineers or managers. } \\
\text { SI considers the socioeconomic impact of water shortage in its definition. } \\
\text { The SI is calculated by the annual deficit rate, and the characteristics of seasonal } \\
\text { deficit and the continuity of daily deficit cannot appear in the values of SI, and } \\
\text { it has no any general criterion for water resources planning. }\end{array}$ \\
\hline $\begin{array}{c}\text { Deficit Percent Day } \\
\text { Index, DPD } \\
{[17,18]} \\
\sum(D D R(\%) \times N D S D)\end{array}$ & Shortcomings & $\begin{array}{l}\text { The DPD is applied to understand the present tolerance of the water users and } \\
\text { serves as a consideration of water resources managers in regulating the water } \\
\text { supply during a specific period. } \\
\text { The DPD can show the tolerance of the water users for various combinations of } \\
\text { daily water shortage density and its duration from the questionnaire. } \\
\text { The DPD is purely based on the water users revealing their tolerance for } \\
\text { various water deficit situations, it is not suitable to serve as the criterion of } \\
\text { long-term water resources planning. }\end{array}$ \\
\hline $\begin{array}{l}\text { Generalized Shortage } \\
\text { Index, GSI } \\
\quad[19] \\
\frac{100}{N} \sum_{t=1}^{N}\left(\frac{D P D_{t}}{100 \times N D Y_{t}}\right)^{2}\end{array}$ & $\begin{array}{l}\text { Advantages } \\
\text { Shortcomings }\end{array}$ & $\begin{array}{l}\text { The GSI is applied to evaluate the relative water deficit situation with given } \\
\text { schemes of water supply system design during the simulation period (both } \\
\text { long-term and short-term) for professional engineers or managers. } \\
\text { The GSI is a modified form from the SI, and it is calculated by the daily deficit } \\
\text { rate; this consideration makes it react sensitively to water shortages. } \\
\text { It has no general criterion for water resources planning. }\end{array}$ \\
\hline
\end{tabular}


1. Water-use index, WI $[14,15]$

The water-use index defines the level of water shortage in a real water supply-demand situation, and can be expressed as:

$$
W I=\frac{W_{S}}{W_{D}}
$$

where, $W_{S}$ is the water supply, and $W_{D}$ is the water demand. $W I$ is a quantitative index that is used to evaluate the level of a water shortage. This index, which is used by the Taiwan Water Corporation, has five levels, which are shown in Table 2.

Table 2. The classification of water-use Index (The standard of Taiwan Water Corporation).

\begin{tabular}{cc}
\hline Deficit Level & Interval of WI \\
\hline Normal & $1 \sim 0.95$ \\
Moderately Deficient & $0.94 \sim 0.85$ \\
Deficient & $0.84 \sim 0.80$ \\
Severely Deficient & $0.79 \sim 0.70$ \\
Extremely Deficient & $<0.7$ \\
\hline
\end{tabular}

2. Shortage index, SI [16]

The shortage index can be defined as follows:

$$
S I=\frac{100}{N} \sum_{t=1}^{N}\left(\frac{A S_{t}}{A D_{t}}\right)^{2}
$$

where, $N$ is the number of evaluation years, $A S_{t}$ is the annual shortage amount in year $\mathrm{t}$, and $A D_{t}$ is the annual water demand amount in year $t$. This index has been used in the United States to evaluate water shortages in connection with reservoir construction [19]. The definition of SI is based on the consideration that the socioeconomic impact of a water shortage is proportional to the square of the shortage ratio. Therefore, if the annual water shortage rate is doubled every year, the SI value would be quadrupled. Moreover, the SI index also incorporates shortage frequency. For example, if the evaluation period is 100 years and the SI value is 1 , the SI value of a $10 \%$ annual shortage rate that occurs once every year is equal to that of a $50 \%$ annual shortage that occurs four times in 100 years. This can be explained as follows:

$$
\frac{100}{100}\left(100 \times 0.1^{2}\right)=\frac{100}{100}\left(4 \times 0.5^{2}\right)
$$

Therefore, the same SI values may result from different combinations of deficit characteristics, and it lacks a general criterion for water resource planning under uncertain hydrological conditions. In addition, since the SI is calculated by the annual deficit rate, the characteristics of seasonal deficit and the continuity of daily deficit cannot appear in the SI values.

\section{Deficit Percent Day Index, DPD}

The Japan Water Resources Development Public Corp. $[17,18]$ proposed the deficit percent day index to include the deficit magnitude and duration in the water shortage index. The deficit percent day index can be defined as follows:

$$
D P D=\sum(D D R(\%) \times N D S D)
$$

where, DDR denotes the daily deficit rate, and NDSD denotes total number of days that the water shortage event lasts for. Huang [17] conducted a questionnaire on the severe water shortage after the 1964 Tokyo Summer Olympics in Japan and reported a DPD of approximately 1000-1500 percent-day. 
The deficit percent day index evaluates the deficit magnitude with the concept of "\%-day", however this only represents the summation of the indicated values for all deficit events, and does not account for the frequency. Therefore, the DDR is unable to predict the water supply capability of a water resource system over the long-term period when used as the standard/criterion of a water supply.

4. Generalized Shortage Index, GSI

Hsu [19] proposed a generalized shortage index (GSI) that incorporates all of the essential aspects of SI and DPD. The Generalized Shortage Index is defined as follows:

$$
G S I=\frac{100}{N} \sum_{t=1}^{N}\left(\frac{D P D_{t}}{100 \times N D Y_{t}}\right)^{2}
$$

where, $N$ is the number of evaluation years, $N D Y_{t}$ denotes the total number of days in year $t$ (365 or 366 ), and $D P D_{t}$ denotes the sum of all DPDs during year $\mathrm{t}$. The GSI is derived from the SI. In this method, SI calculates the annual deficit rate by using the daily deficit rate, as clarified in the following formula:

$$
G S I=\frac{100}{N} \sum_{t=1}^{N}\left(\frac{\sum_{\delta=1}^{N D Y_{t}}\left(\left(\frac{D S_{\delta, t}}{D D_{\delta, t}}\right) \times 100(\%)\right) \times N D C D}{100 \times N D Y_{t}}\right)^{2}
$$

where, $D D_{\delta}$ denotes the daily demand on day $\delta$, and $D S_{\delta}$ denotes the daily shortage on day $\delta$. Hsu [19] addressed that the GSI can make up for the weaknesses of SI, which cannot assess the detailed characteristics of a water shortage with the annual water deficit rate. We can also say that the GSI uses the daily shortage rate instead of the annual shortage rate as the basic consideration of socioeconomic impact, which means that GSI is sensitive to the effects of shortage events during the same evaluated period. However, the GSI also lacks a general criterion for water resources planning under uncertain hydrological conditions.

The purpose of this sub-section is to illustrate the performance of the currently used indexes with regard to examining the effects of water shortages. The reasons why GSI/SI served as the indicator of water supply evaluation are described in the following sub-section. Table 1. The comparison of four common water shortage evaluation indexes.

\subsection{The Present Problem of Water Supply Evaluation for Water Supply Reservoir/System Planning}

Under uncertain hydrological conditions, it is difficult for reservoir regulations to satisfy a given requirement completely during a critical dry period, and even if the reservoir has a huge capacity it could provide a higher and more stable yield. Therefore, a small amount of shortage could be allowed with economic conditions of a reservoir construction through the evaluation of the water supply potential. The Shortage Index (SI), which was invented by the U.S. Army Corps of Engineers, has been adopted in Taiwan since 1985 to evaluate the potential water supply in the reservoir planning stage [17]. However, to date, the SI value lacks a general criterion for its application under uncertain hydrological conditions. In principle, the best operation of a water supply system is to make the object function of the SI close to 0 . In practice, the water supply potential of a reservoir is estimated using the shortage index, $\mathrm{SI}=\mathrm{A}$, which is utilized as the planning indictor (ordinary $\mathrm{A}=1.0$, and $\mathrm{SI}=1$ is a conceptual value which allows a $10 \%$ annual shortage rate that occurs once every year.). The flowchart of the status quo in Taiwan is shown in the left hand side of Figure 2. A simulation is then conducted for fine-tuning and to interpolate the maximum water supply amount that meets the condition of SI $=\mathrm{A}$. The maximum water supply amount is used as the planned water supply amount along with the historical reservoir inflow series to evaluate the reliability of the water supply of SI = A [20-22]. If the water supply situation (the combinations of shortages' intensity and frequency) can be accepted by water resource 
managers, then further water supply system organization is conducted based on the value of SI. Otherwise, the value of SI needs to be adjusted based on the opinions of engineers/managers with regard to the local physiographical and hydrological conditions until the water supply situation reaches engineers/managers' opinions for an acceptable level. In general, the SI is increased in proportion to the variance of streamflow. The final definition of the SI value is dependent on the managers' judgment, while they use a given design to regulate the variance of streamflow for a given demand, and then, based on the final designed scheme, draw up the more advanced water supply system organization (such as the rule curve, regional regulation policy, and so on.). Therefore, it is difficult to explain the effect of the water supply situation on water users using the SI value, and without an exact criterion which engineers can utilize to plan a water supply system.

\section{The status quo in The proposed study Taiwan}
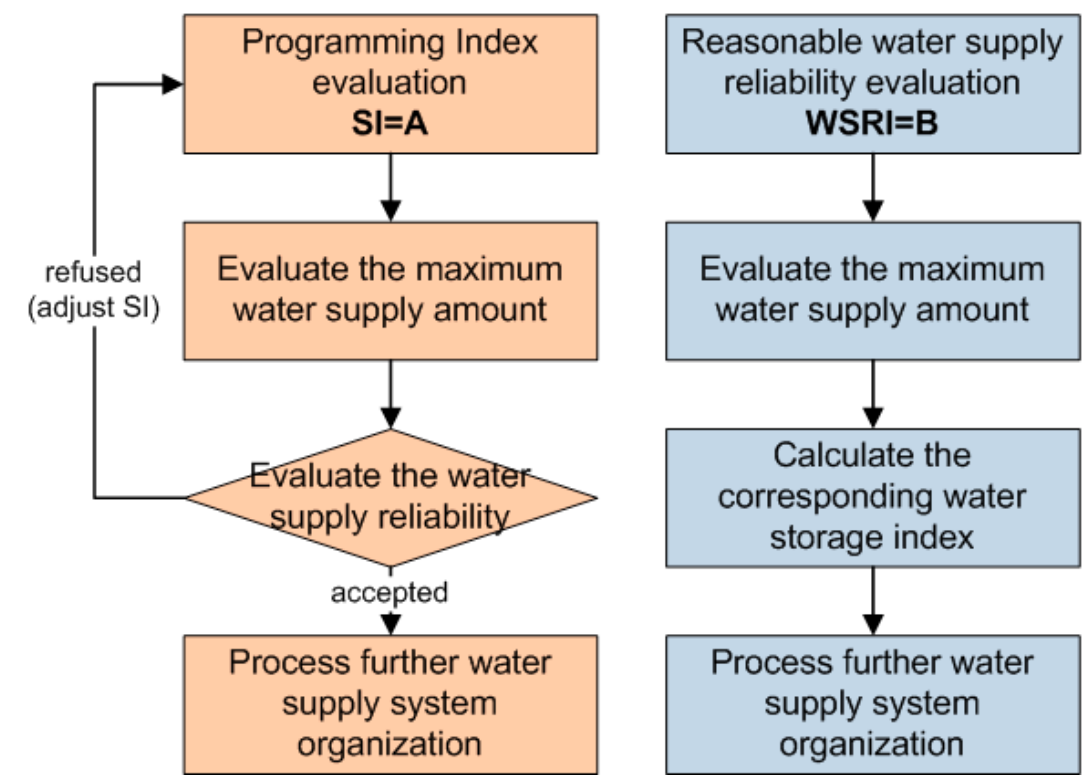

Figure 2. Illustration of different considerations between the status quo and this study.

Fauchon [12] found that most water supply systems face several challenges, including demographic growth, deforestation, soil degradation and climate change. For a given water supply system, these challenges that lead to shortages raise new problems for engineers and managers with regard to changing designs to meet demand. To date, however, no clear direction has emerged to suggest how considerations about hydrological and physiographical conditions can be translated into indicators to provide information about the potential risks to a given water supply system. To overcome these shortcomings, a new approach to evaluate the maximum water supply potential and its corresponding reliability under the limitations of hydrological and physiographical conditions in different planning sites is presented in this paper.

\subsection{The Basic Consideration of this Study}

The purpose of using SI was to minimize the socioeconomic impact from various feasible schemes and to select the appropriate one as the final submission for water demand. The appropriate scheme is a compromise solution between the natural restrictions and the cost effective conditions. Although the final solutions for SI may have similar corresponding water supply reliabilities in different planning sites, according to the definition of SI, it is difficult to explain the criteria for the final planning scheme, and managers cannot provide a good illustration of the water shortage risk under the condition of $\mathrm{SI}=\mathrm{A}$ to the general public who lives in different water supply areas. To determine whether water 
supply could meet the demands of the final planning scheme, this study employed the water supply degree of satisfaction during the operation period to represent the water supply reliability and offers an alternative method of planning the water supply amount through the use of the water supply reliability index (WSRI). Therefore, this study offers a reverse way of thinking about planning the water supply amount with the use of the water supply reliability index (WSRI). Different considerations for evaluating and comparing the commonly used indexes and that presented in this study are illustrated in Figure 2. The water supply reliability hinges upon the water supply potential in a planning site, and the water supply potential is restricted by the local physiographic and hydrological conditions. Therefore, if the water supply reliability and the local conditions could be better known before developing a project, then engineers would be able to provide better information to the general public and be able to work with more appropriate plans.

Since reservoirs are the most important facilities in water supply systems, this study investigates the maximum water supply potential of reservoirs in different hydrological and physiographical conditions from the perspective of the planning stage, and explores the relationship between the values of the present use shortage index and its corresponding water supply reliability. In this study, two subjects are discussed. The first is a correlation analysis between the water supply reliability and SI value. The second is an estimation of reservoir reasonable water supply reliability in a planning site. The core of the investigation is to find out the interpretative variables for the local conditions and then identify the relationships among the interpretative parameters, water supply reliability, and the present use shortage index in the selected study cases. In order to clarify the relative contribution of these variables, stepwise multiple regression analysis is undertaken. Finally, the reasonable water supply reliability value for a new planning site is obtained with an estimation function that combines several dimensionless parameters of the reservoir systems' characteristics. For existing reservoirs, the evaluation method could serve as an explanation for both the exploitation and regulation of water resources. The flowchart of this study is shown in Figure 3, and is described as follows.

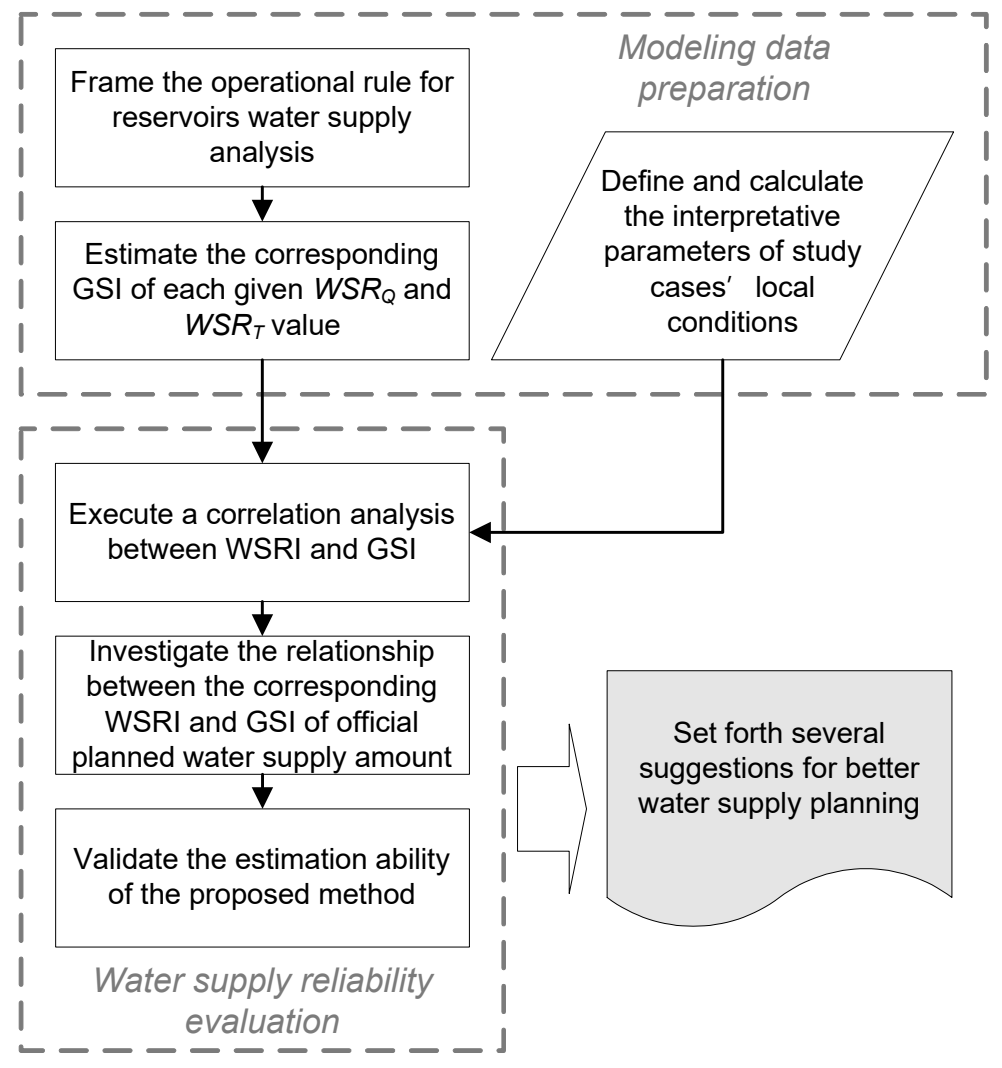

Figure 3. Flowchart of proposed methodology. 
1. Frame the operational rule for reservoirs water supply analysis:

In the reservoir water supply analysis, the reservoir net inflow data obtained from the flow discharge record of the catchment area of the reservoir deducts the downstream water rights and the environmental flow. For the environmental flow, since this work is focused on the discussion of reservoir water supply potential, although many studies [23-25] have provided extensive discussions on the issue of environmental flow reservation, there are still no official criteria on the environmental flow in Taiwan. Therefore, environmental flow employs the common informal rule that appears in the related reports of water resources project in Taiwan as the criterion used in this study to undertake the water supply analysis. The reservoir water supply analysis then employs the continuity equation $I-O=d s / d t$, to calculate the water shortage rate under the different assumed water supply amount conditions. Three different reservoir operation types are included in this study: (A) a single reservoir operation without transbasin diversion, (B) a single reservoir operation with transbasin diversion, and (C) a joint operation with a weir. The system frameworks are illustrated in Figure $4 a-c$, respectively. These reservoir operation simulations are based on the given developed reservoir capacity scale without considering the specific water supply situation, and with the assumption that they were all single purpose reservoirs for public water supply.

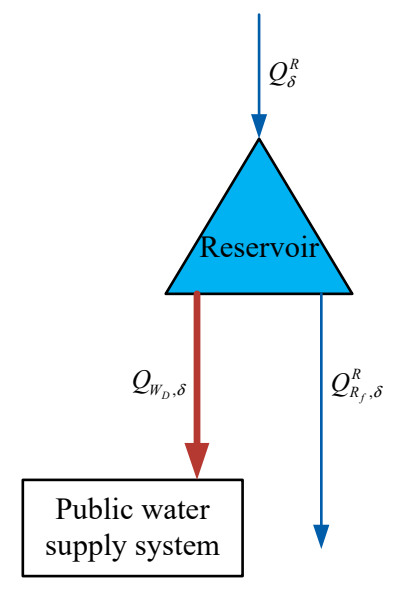

(a) Single reservoir operation without transbasin diversion

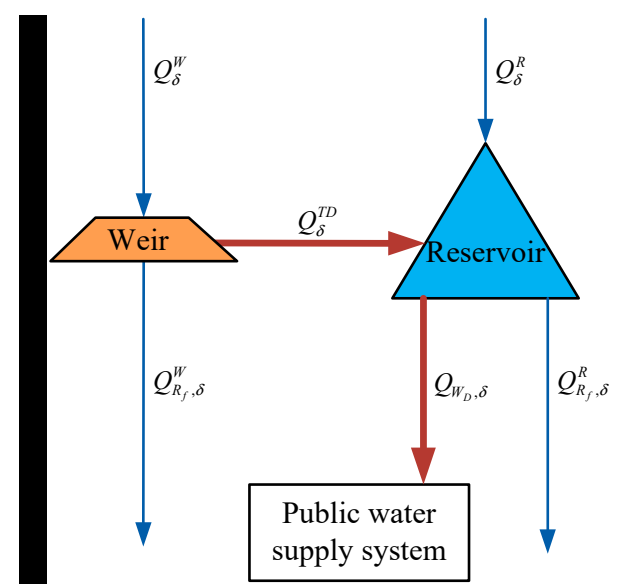

(b) Single reservoir operation with transbasin diversion
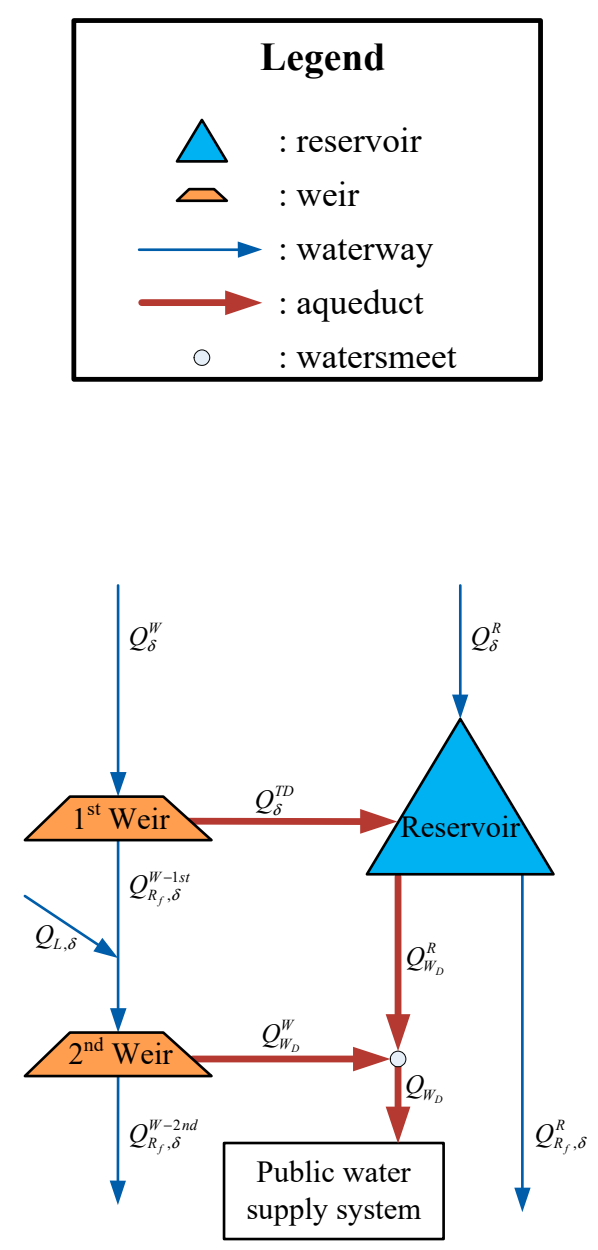

(c) Joint operation with a weir

Figure 4. The operation rule of single reservoir and joint operation. 
The simulation rules, basic assumptions and steps are explained below:

(A) Single reservoir operation without transbasin diversion

The available surplus flow of the reservoir site (i.e., reservoir net inflow, $I_{\delta}^{R}$ ) is defined as follows:

$$
I_{\delta}^{R}=Q_{\delta}^{R}-\hat{Q}_{R_{f}, \delta}^{R}
$$

where, $Q_{\delta}^{R}$ denotes the natural flow discharge of the reservoir catchment area on day $\delta$, and $\hat{Q}_{R_{f}, \delta}^{R}$ denotes the actual reserved flow of the reservoir downstream on day $\delta$, and the superscript $R$ is the label of reservoir. $\hat{Q}_{R_{f}, \delta}^{R}$ is obtained using a comparison among $Q_{\delta}^{R}, Q_{R_{f}, \delta^{\prime}}^{R} Q_{W_{R}, \delta^{\prime}}^{R} Q_{E, \delta^{\prime}}^{R}$ and $Q_{95 \%}^{R}$ and represents the natural flow discharge of the reservoir catchment area on day $\delta$, the reservoir downstream required reserved flow on day $\delta$, the amount of reservoir downstream water right on day $\delta$, the reservoir downstream environmental flow on day $\delta$, and the corresponding reservoir main streamflow of $95 \%$ exceedance probability respectively. Judging from the formulas $\hat{Q}_{R_{f}, \delta}^{R}=$ $\min \left\{Q_{\delta}^{R}, Q_{R_{f}, \delta}^{R}\right\}, Q_{R_{f}, \delta}^{R}=\max \left\{Q_{W_{R}, \delta^{\prime}}^{R}, Q_{E, \delta}^{R}\right\}$, and $Q_{E, \delta}^{R}=\min \left\{Q_{95 \%}^{R}, Q_{\delta}^{R}\right\}$ to determine the actual reserved flow of the reservoir downstream on day $\delta$, the reservoir downstream required the reserved flow on day $\delta$, and the reservoir downstream environmental flow on day $\delta$, respectively.

(B) Single reservoir operation with transbasin diversion

There are two inflow sources in the reservoir; one is the reservoir main stream, the other is the transbasin diversion. The reservoir's available surplus flow could be represented as follows:

$$
I_{\delta}^{R}=Q_{\delta}^{R}-\hat{Q}_{R_{f}, \delta}^{R}+Q_{\delta}^{T D}
$$

where, $Q_{\delta}^{T D}$ denotes the transbasin diversion on day $\delta . Q_{\delta}^{T D}$ is obtained using the comparison between the actual available main streamflow of weir $\hat{Q}_{\delta}^{W}$ and the diversion tunnel effective capacity $T C_{E f f}$. The $Q_{\delta}^{T D}$ could be represented as

$$
\begin{gathered}
Q_{\delta}^{T D}=\min \left\{\hat{Q}_{\delta}^{W}, T C_{E f f}\right\} \\
\hat{Q}_{\delta}^{W}=Q_{\delta}^{W}-\hat{Q}_{R_{f}, \delta}^{W}
\end{gathered}
$$

where, the superscript TD and $\mathrm{W}$ are the label of transbasin diversion and weir respectively, while $T C_{E f f}$ denotes the diversion tunnel effective capacity that the transmission loss is considered. When the transmission loss measures $10 \%$, it can be denoted as $T C_{E f f}=T C_{\max } \times 90 \%$. The $\hat{Q}_{\delta}^{W}$ was obtained by doing a comparison among $Q_{\delta}^{W}, Q_{R_{f}, \delta^{\prime}}^{W} Q_{W_{R}, \delta^{\prime}}^{W} Q_{E, \delta^{\prime}}^{W}$ and $Q_{95 \%}^{W}$, which represents the main streamflow of the weir on day $\delta$, the weir downstream required reserved flow on day $\delta$, the amount of the weir downstream water right on day $\delta$, the weir downstream environmental flow on day $\delta$, and the corresponding weir main streamflow of $95 \%$ exceedance probability, respectively, using the formulas of $\hat{Q}_{R_{f}, \delta}^{W}=\min \left\{Q_{\delta}^{W}, Q_{R_{f}, \delta}^{W}\right\}, Q_{R_{f}, \delta}^{W}=\max \left\{Q_{W_{R}, \delta^{\prime}}^{W} Q_{E, \delta}^{W}\right\}$, and $Q_{E, \delta}^{W}=\min \left\{Q_{95 \%}^{W}, Q_{\delta}^{W}\right\}$ to determine the actual weir downstream reserved flow on day $\delta$.

After calculating the available surplus flow, the results are used to undertake the water supply analysis using the reservoir net inflow and the conservation storage (given the developed reservoir scale) as the provider and the planning water supply amount of downstream as the requirement. The water supply analysis is conducted using the conditions of the water release policy that were mentioned above and the fixed daily water supply amount to evaluate the extent of the water deficit (for volume and time).

The water balance constraint for the single reservoir water supply analysis is:

$$
S_{\delta+1}=S_{\delta}+I_{\delta}^{R}-Q_{W_{D}, \delta}-E_{\delta}
$$


where, $S_{\delta}$ and $S_{\delta+1}$ are the reservoir storage on day $\delta$ and day $\delta+1, Q_{W_{D}, \delta}$ is the water supply system release flow for water demand on day $\delta$, and $E_{\delta}$ is evaporation loss on day $\delta$.

(C) Joint operation with a weir

The system diagram is shown in Figure 4c. The daily demand of the joint operation system is supplied by the 2nd weir in advance, along with the reservoir release, to make up the deficit. The available surplus flow of the reservoir could be obtained with Formula (8). The reservoir water supply analysis is then undertaken with the water balance constraint given by Formula (11), where, $I_{\delta}^{R}$ is defined as $Q_{\delta}^{R}-\hat{Q}_{R_{f}, \delta}^{R}+\left(\min \left\{\left(Q_{\delta}^{W}-Q_{R_{f}, \delta}^{W-1 s t}\right), T C_{E f f}\right\}\right)$, and $Q_{R_{f}, \delta}^{W-1 s t}$ denotes the 1st weir reserved flow to the downstream. The water supply situation can be obtained as follows:

$$
Q_{W_{D}, \delta}=Q_{W_{D}, \delta}^{W}+Q_{W_{D}, \delta}^{R}
$$

where, $Q_{W_{D}, \delta}^{W}$ is the weir released flow for water demand on day $\delta$, which was considered with the lateral flow $Q_{L, \delta}$, and the 2nd weir reserved flow to the downstream $Q_{R_{f}, \delta}^{W-2 n d}$ and obtained from:

$$
Q_{W_{D}, \delta}^{W}=Q_{\delta}^{W}-Q_{\delta}^{T D}+Q_{L, \delta}-Q_{R_{f}, \delta}^{W-2 n d}
$$

and $Q_{W_{D}, \delta}^{R}$ denotes the reservoir release flow for water demand on day $\delta$.

Daily shortage situations for both the single and joint reservoir operation can be defined as follows:

$$
D S_{\delta}=\left\{\begin{array}{cc}
\left|Q_{W_{D}, \delta}-D W_{P S}\right| & , \text { if } Q_{W_{D}, \delta}<D W_{P S} \\
0 & , \text { otherwise }
\end{array}\right.
$$

where, $D S_{\delta}$ denotes the daily shortage on day $\delta, D W_{P S}$ denotes the daily water supply amount, and the day that the shortage event occurred is denoted as 1 within $D S E N_{\delta}$, can be represented as follows:

$$
D_{S E N}=\left\{\begin{array}{c}
1, \text { if } Q_{W_{D}, \delta}<D W_{P S} \\
0, \text { otherwise }
\end{array}\right.
$$

where $D S E N_{\delta}$ denotes the daily shortage event record on day $\delta$, when the value of $D S E N_{\delta}$ is 1 the water supply is deficient on day $\delta$, when the value of $D S E N_{\delta}$ is 0 the water supply meets the water supply amount on day $\delta$. The volumetric reliability $W S R_{Q}$ and time reliability $W R S_{T}$ of the water supply during the simulated period can then be defined as follows:

$$
\begin{array}{r}
W S R_{Q}=\frac{\sum_{t=1}^{N} \sum_{\delta=1}^{N D Y_{t}}\left(D S_{\delta, t}\right)}{\sum_{t=1}^{N} \sum_{\delta=1}^{N D Y_{t}}\left(D W_{P S, \delta, t}\right)} \\
W S R_{T}=\frac{\sum_{t=1}^{N} \sum_{\delta=1}^{N D Y_{t}}\left(D S_{\delta, t}\right)}{\sum_{t=1}^{N} N D Y_{t}}
\end{array}
$$

where, $D S_{\delta, t}$ is the daily shortage on day $\delta$ in year $\mathrm{t}$, and $D W_{P S, \delta, t}$ is the daily water supply amount on day $\delta$ in year t.

In principle, the reliability of a reservoir is defined as the probability that it will deliver the expected demand throughout its lifetime without incurring any deficiency [26]. To illustrate the differences of shortage event behavior for time and volume, this study divided the reliability into two components: $W S R_{T}$ and $W S R_{Q}$ respectively. 
2. Estimate the Corresponding GSI of Each Given $\mathrm{WSR}_{\mathrm{Q}}$ and $\mathrm{WSR}_{\mathrm{T}}$ Value:

The maximum water supply amount could be obtained by simulation against different water supply reliability values, and then the corresponding GSI of each given $W S R_{Q}$ and $W S R_{T}$ value can be estimated for each reservoir.

3. Define and Calculate the Interpretative Parameters of the Study Cases' Local Conditions:

Four dimensionless parameters are created or selected to investigate the maximum water supply potential of reservoirs in different hydrological and physiographical conditions to evaluate the reasonable water supply reliability function:

Parameter 1: Reservoir capacity factor, $K F$

$$
K F=\frac{K}{\overline{A I^{R}}}
$$

where, $K$ denotes the effective reservoir capacity, and $\overline{A I^{R}}$ denotes the average annual reservoir net inflow. $K F^{-1}$ means the average annual reservoir operation times [27]. For the same given target of water supply reliability, annual-use-reservoirs need different annual reservoir operation times to reach the target according to the specific hydrological conditions. Further, since the reservoir capacity plays a vital role in shifting water from wet to dry periods, increases in capacity can improve water supply reliability, and hence, the definition of $K F$ and the regulation ability of the reservoir have been shown to be positively correlated [28,29]. For the reasons mentioned above, the parameter $K F$ is employed to explain the influence of effective reservoir capacity on the control of water resources.

Parameter 2: Reservoir net inflow variation $C V_{I^{R}}$

$$
C V_{I^{R}}=\frac{\hat{s}_{A I^{R}}}{\overline{A I^{R}}}
$$

where, $C V_{I^{R}}$ denotes the coefficient of variation of the reservoir net inflow, and $\hat{s}_{A I^{R}}$ is the standard deviation of the annual reservoir net inflow.

Parameter 3: Reservoir net inflow ratio of dry to wet seasons, DWIR

$$
D W I R=\frac{\sum_{t=1}^{N} I_{D S, t}^{R}}{\sum_{t=1}^{N} I_{W S, t}^{R}}
$$

where, $I_{D S, t}^{R}$ is the reservoir total net inflow during the dry season (in Taiwan, the dry season is from November to April) in year $\mathrm{t}$, and $I_{W S, t}^{R}$ is the reservoir total net inflow during the wet season (in Taiwan, the wet season is from May to October) in year $\mathrm{t}$.

The parameters $C V_{I^{R}}$ and DWIR are used to explain variations in the reservoir net inflow in contrast with reservoir locations or operational forms (on-stream or off-stream).

Parameter 4: Time ratio of wet to dry days, WDTR

$$
W D T R=\frac{N D_{I_{t}^{R}>\overline{I^{R}}}}{N D_{I_{t}^{R}<I^{R}}}
$$

where, $N D_{I_{t}^{R}>T^{R}}$ is the total number of days for which the reservoir net inflow is greater than the average reservoir net inflow, and $N D_{I_{t}^{R}<I^{R}}$ is the total number of days that the reservoir net inflow is smaller than the average reservoir net inflow. The parameter WDTR is used to explain variations in the reservoir net inflow time distribution in contrast with reservoir locations. 
In order to make a positive correlation between the parameters and the reservoir regulation ability, the definitions of DWIR and WDTR have different wet and dry considerations.

The water supply analysis adopts the reservoir net inflow as simulation data, and thus the characteristics of the on-stream and off-stream reservoirs are included in four dimensionless parameters, as mentioned above. If the rule of the joint operation can be identified, then the effect of the joint operation should also be included in those four dimensionless parameters.

1. Execute a correlation analysis between WSRI and GSI:

In order to investigate the correlation between the WRSI and GSI values, this study employs a linear regression model to establish the relation function with the dependent variable, WSRI, and the independent variables GSI, $K F, C V_{I^{R}}$, and WDTR.

2. Investigate the relationship between the corresponding WSRI and GSI values of the official planned water supply amount

3. Validate the estimation ability of the proposed method.

4. Set forth several suggestions for better water supply planning (both given and new planning sites).

\section{Case Study}

\subsection{Data Arrangement}

\subsubsection{Description of the Case Study}

Ten reservoirs that were either built or in the planning stage were selected from north, central and south Taiwan. The same record period 39 years was used for all the reservoirs in the case study, and more information on the reservoirs is listed in Table 3, while their locations of the reservoirs are shown in Figure 5. Half the reservoirs were on-stream ones and half off-stream ones. The on-stream reservoirs included the Feitsui Reservoir, Shihmen Reservoir, Bilin Reservoir, Mingde Reservoir, and Mutan Reservoir. The off-stream reservoirs included the Tianhuahu Reservoir, Liyutan Reservoir, Jianming Reservoir, Hushan Reservoir, and Nanhua Reservoir. The Nanhua Reservoir, jointly operating with the Gaopingsi weir, was considered to be a joint operation case.

Table 3. Basic information about the selected study cases.

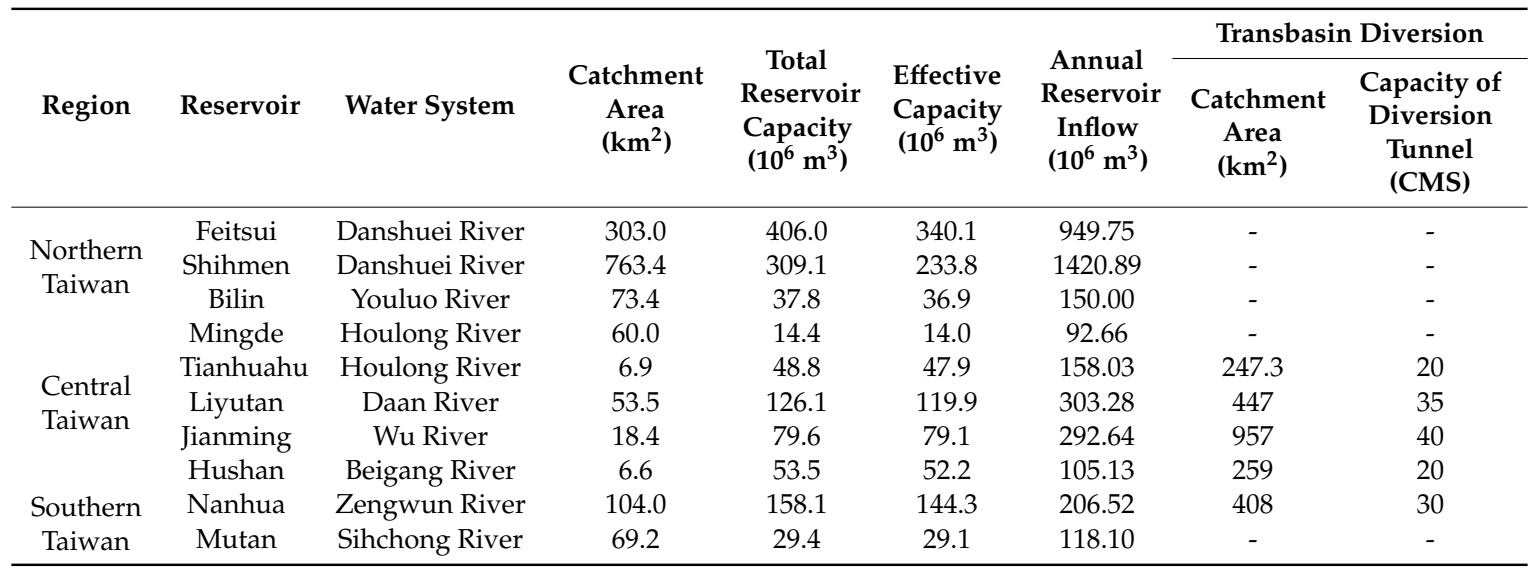



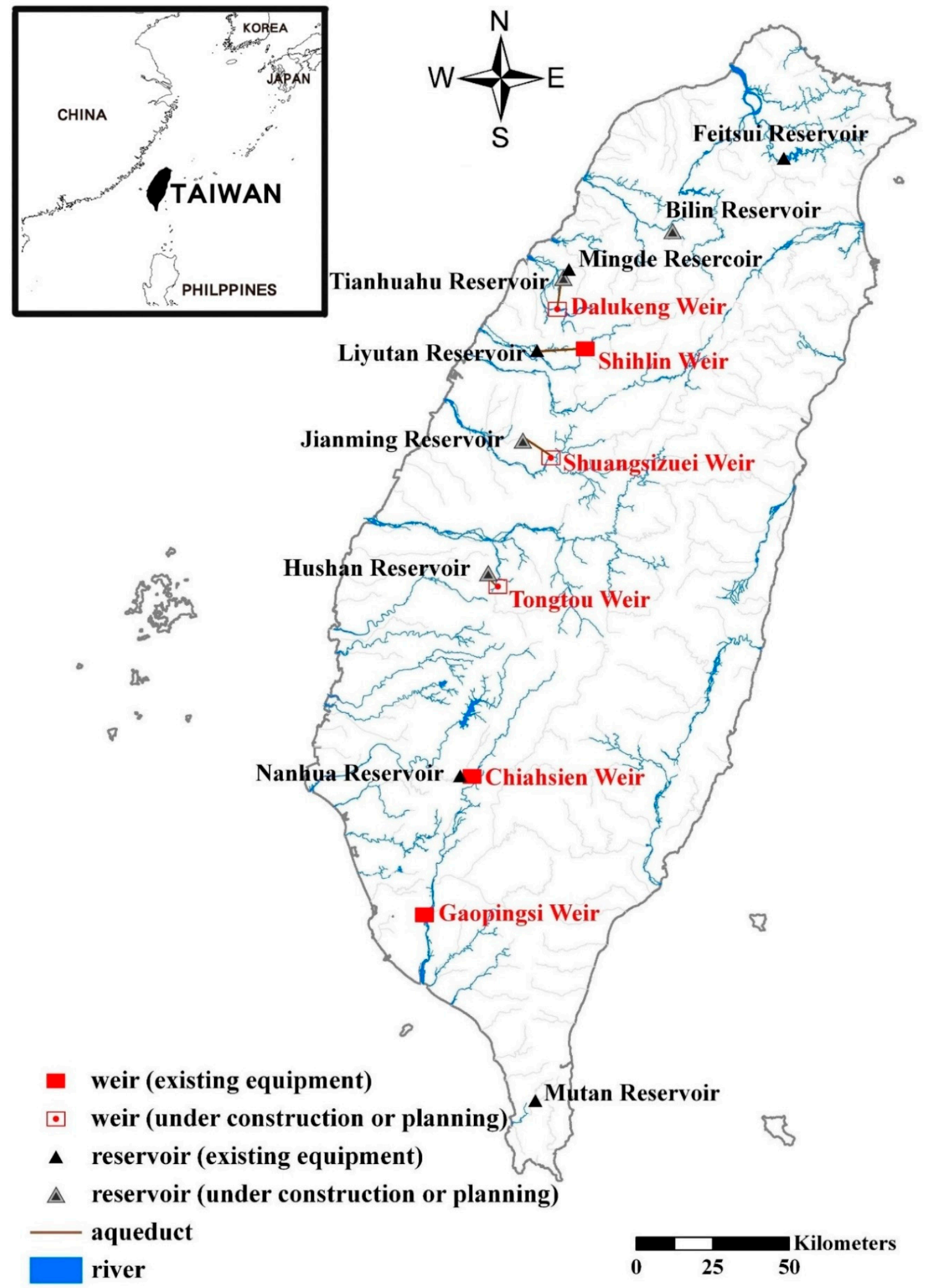

Figure 5. The location of selected cases. 


\subsubsection{Selection of Hydrological Data}

The reservoir water supply analyses were all taken from the same period of hydrological data, from 1959 to 1997. The reservoir net inflow duration curves for each selected reservoir case are shown in Figure 6. This figure gives the distributions of the reservoirs' net inflow during the study period, and curves which end at less than $100 \%$ mean that the corresponding reservoir net flow is equal to 0 after the last point. The simulation's rules, basic assumptions and steps were explained in the previous section. The consideration of the environmental flow was based on the gauged streamflow of the reservoir and weir sites during the simulation period from 1959 to 1997. The evaporation loss of each simulation step was obtained by measuring the corresponding reservoir surface area from the former simulation step. The initial reservoir storage was assumed to be half the effective reservoir capacity for both the systems, single and joint operations. Any initial conditions could influence the results of the system operation. Thus, the following evaluation and calculation related to water shortage characteristics excluded the first year results of the reservoir water supply simulation to avoid any possible disturbances.

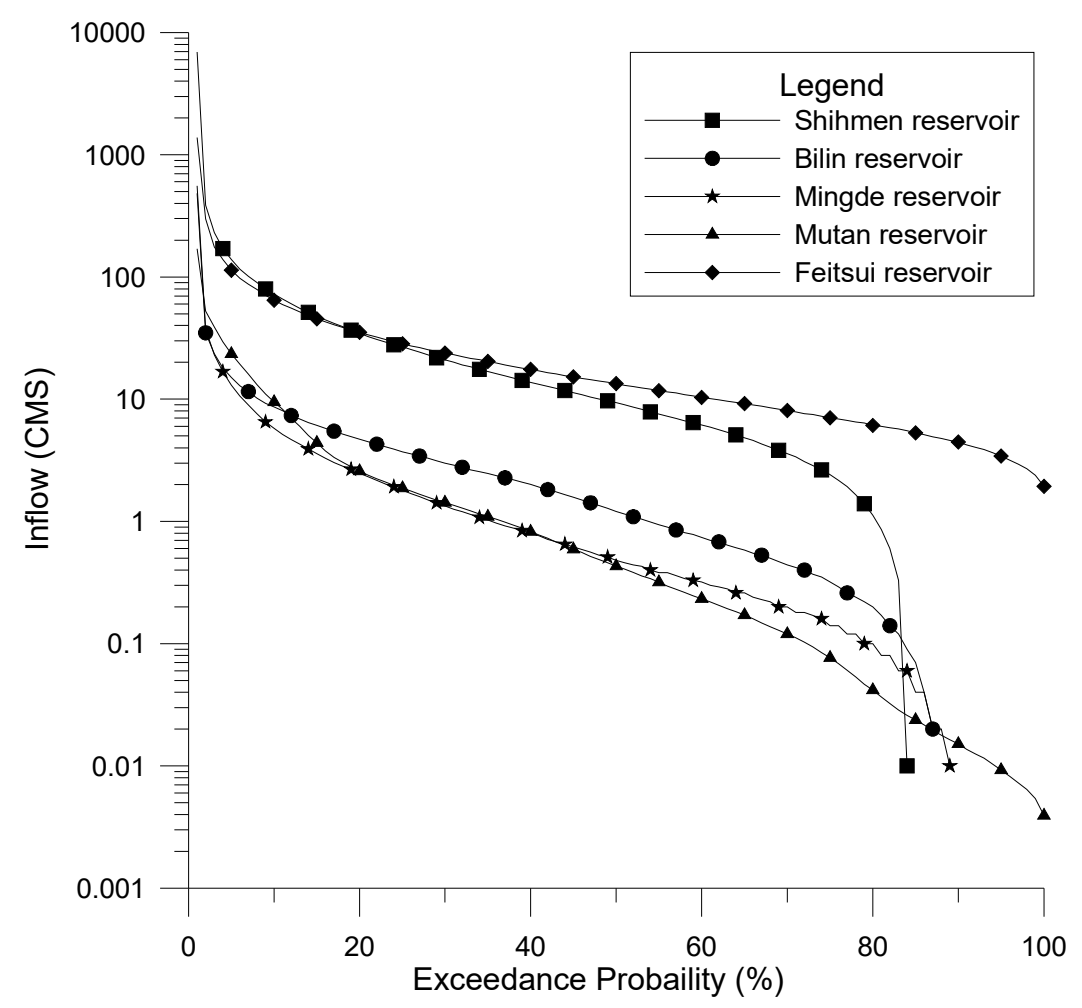

(a) Single reservoir operation without transbasin diversion

Figure 6. Cont. 


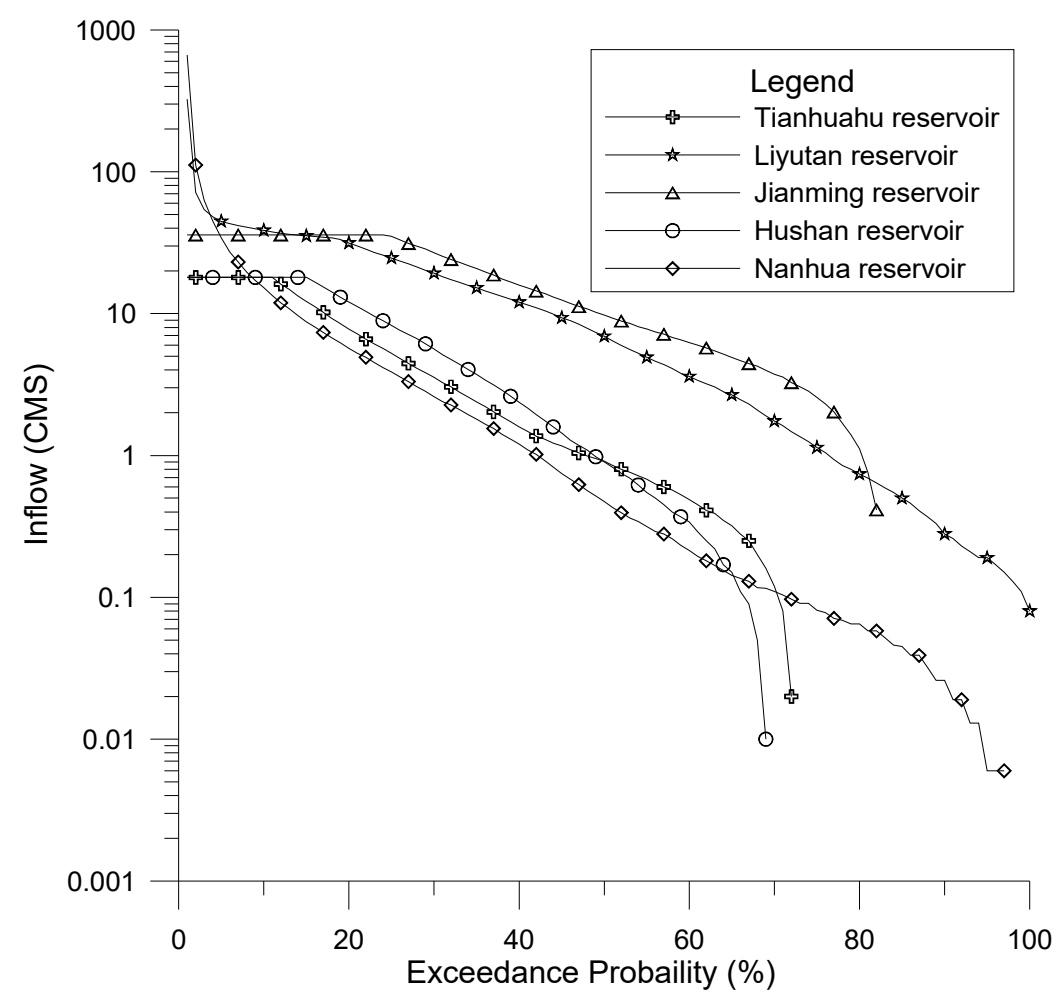

(b) Single reservoir operation with transbasin diversion

Figure 6. The net inflow duration curve of each selected reservoir case.

\subsection{Model Establishment and Estimation Results}

\subsubsection{Data Preparation}

In accordance with the calculation steps, the first move is to accomplish the basic data analysis. The evaluation intervals of water supply reliability start from 0.975 and are spaced at 0.25 until 0.75 . The water supply characteristics are calculated against the given value settings of time and volumetric water supply reliability with the reservoir net inflow, including the maximum water supply amount and the corresponding GSI of the maximum water supply amount. Numerous output tables were produced for the routing results, and those for the Shihmen reservoir are used as an example in Tables 4 and 5 . Table 4 lists the corresponding maximum water supply amount of each combination between time and volumetric reliability for the Shihmen reservoir during the evaluation period from 1960 to 1997. The corresponding GSI values for Table 4 are listed in Table 5.

Table 4. The maximum water supply amount of each reliability condition for the Shihmen reservoir (Unit: CMS).

\begin{tabular}{ccccccccccc}
\hline Volume $\backslash$ Time & $\geq \mathbf{0 . 9 7 5}$ & $\mathbf{0 . 9 5 0}$ & $\mathbf{0 . 9 2 5}$ & $\mathbf{0 . 9 0 0}$ & $\mathbf{0 . 8 7 5}$ & $\mathbf{0 . 8 5 0}$ & $\mathbf{0 0 . 8 2 5}$ & $\mathbf{2 0 . 8 0 0}$ & $\geq \mathbf{0 . 7 7 5}$ & $\geq \mathbf{0 . 7 5 0}$ \\
\hline$\geq 0.975$ & 16.7 & 16.7 & 16.7 & 16.7 & 16.7 & 16.7 & 16.7 & 16.7 & 16.7 & 16.7 \\
$\geq 0.950$ & 16.7 & 18.2 & 18.6 & 18.6 & 18.6 & 18.6 & 18.6 & 18.6 & 18.6 & 18.6 \\
$\geq 0.925$ & 16.7 & 18.2 & 19.5 & 20.1 & 20.1 & 20.1 & 20.1 & 20.1 & 20.1 & 20.1 \\
$\geq 0.900$ & 16.7 & 18.2 & 19.5 & 20.9 & 21.5 & 21.5 & 21.5 & 21.5 & 21.5 & 21.5 \\
$\geq 0.875$ & 16.7 & 18.2 & 19.5 & 20.9 & 22.1 & 22.8 & 22.8 & 22.8 & 22.8 & 22.8 \\
$\geq 0.850$ & 16.7 & 18.2 & 19.5 & 20.9 & 22.1 & 23.2 & 24.0 & 24.0 & 24.0 & 24.0 \\
$\geq 0.825$ & 16.7 & 18.2 & 19.5 & 20.9 & 22.1 & 23.2 & 24.2 & 25.2 & 25.3 & 25.3 \\
$\geq 0.800$ & 16.7 & 18.2 & 19.5 & 20.9 & 22.1 & 23.2 & 24.2 & 25.2 & 26.4 & 26.7 \\
$\geq 0.775$ & 16.7 & 18.2 & 19.5 & 20.9 & 22.1 & 23.2 & 24.2 & 25.2 & 26.4 & 27.6 \\
$\geq 0.750$ & 16.7 & 18.2 & 19.5 & 20.9 & 22.1 & 23.2 & 24.2 & 25.2 & 26.4 & 27.6 \\
\hline
\end{tabular}


Table 5. The corresponding GSI of maximum water supply amount for the Shihmen reservoir.

\begin{tabular}{|c|c|c|c|c|c|c|c|c|c|c|}
\hline Volume $\backslash$ Time & $\geq 0.975$ & $\geq 0.950$ & $\geq 0.925$ & $\geq 0.900$ & $\geq 0.875$ & $\geq 0.850$ & $\geq 0.825$ & $\geq 0.800$ & $\geq 0.775$ & $\geq 0.750$ \\
\hline$\geq 0.975$ & 0.25 & 0.25 & 0.25 & 0.25 & 0.25 & 0.25 & 0.25 & 0.25 & 0.25 & 0.25 \\
\hline$\geq 0.950$ & 0.25 & 0.70 & 0.81 & 0.81 & 0.81 & 0.81 & 0.81 & 0.81 & 0.81 & 0.81 \\
\hline$\geq 0.925$ & 0.25 & 0.70 & 1.13 & 1.41 & 1.41 & 1.41 & 1.41 & 1.41 & 1.41 & 1.41 \\
\hline$\geq 0.900$ & 0.25 & 0.70 & 1.13 & 1.85 & 2.20 & 2.20 & 2.20 & 2.20 & 2.20 & 2.20 \\
\hline$\geq 0.875$ & 0.25 & 0.70 & 1.13 & 1.85 & 2.51 & 2.92 & 2.92 & 2.92 & 2.92 & 2.92 \\
\hline$\geq 0.850$ & 0.25 & 0.70 & 1.13 & 1.85 & 2.51 & 3.16 & 3.70 & 3.70 & 3.70 & 3.70 \\
\hline$\geq 0.825$ & 0.25 & 0.70 & 1.13 & 1.85 & 2.51 & 3.16 & 3.83 & 4.57 & 4.66 & 4.66 \\
\hline$\geq 0.800$ & 0.25 & 0.70 & 1.13 & 1.85 & 2.51 & 3.16 & 3.83 & 4.57 & 5.56 & 5.81 \\
\hline$\geq 0.775$ & 0.25 & 0.70 & 1.13 & 1.85 & 2.51 & 3.16 & 3.83 & 4.57 & 5.56 & 6.52 \\
\hline$\geq 0.750$ & 0.25 & 0.70 & 1.13 & 1.85 & 2.51 & 3.16 & 3.83 & 4.57 & 5.56 & 6.52 \\
\hline
\end{tabular}

Since the evaluation period of Tables 4 and 5 excluded the first year results of the reservoir water supply simulation, and the results of Tables 4 and 5 were produced based on 38 years' data, the effect of initial reservoir storage assumption on the results is insignificant. The results in Table 4 indicate that the corresponding maximum water supply amount of each combination between time and volumetric reliability are approximately located on the straight line from top left of the table to the bottom right. Furthermore, since the SI was usually considered as 1 for the initial consideration in the reservoir planning stage, this study collated the study cases' corresponding intervals of time and volumetric reliability for the consideration that $\mathrm{SI}=1$ in order to evaluate their relationship. The results are shown in Table 6, and indicate that the intervals of time reliability $W S R_{T}$ and volumetric reliability $W S R_{Q}$ appear to generally agree. Therefore, this study considers the volumetric reliability $W S R_{Q}$ to be the main analytical index, i.e., the water supply reliability index (WSRI). In addition, the GSI values of each reservoir, which are located on the straight line from the top left of the table to the bottom right, serve as each reservoir's representative values of water supply reliability index. The GSI values of the selected reservoir cases are collated in Table 7.

Table 6. Corresponding water supply reliability of GSI $=1.0$.

\begin{tabular}{cccccc}
\hline & & \multicolumn{4}{c}{ GSI = 1.0 } \\
\cline { 3 - 6 } & Reservoir & \multicolumn{2}{c}{ Time Reliability } & \multicolumn{2}{c}{ Volumetric Reliability } \\
\cline { 3 - 6 } & & Up Bound & Low Bound & Up Bound & Low Bound \\
\cline { 3 - 6 } Northern & Feitsui & 0.950 & 0.925 & 0.950 & 0.925 \\
Taiwan & Shihmen & 0.950 & 0.925 & 0.950 & 0.925 \\
& Bilin & 0.975 & 0.950 & 0.975 & 0.950 \\
& Mingde & 0.925 & 0.900 & 0.925 & 0.900 \\
Central Taiwan & Tianhuahu & 0.950 & 0.925 & 0.950 & 0.925 \\
& Liyutan & 0.950 & 0.925 & 0.950 & 0.925 \\
& Jianming & 0.950 & 0.925 & 0.950 & 0.925 \\
Southern & Hushan & 0.950 & 0.925 & 0.950 & 0.925 \\
Taiwan & Nanhua & 0.975 & 0.950 & 0.975 & 0.950 \\
& Mutan & 0.950 & 0.925 & 0.975 & 0.950 \\
& Joint Operation & 0.925 & 0.900 & 0.950 & 0.925 \\
\hline
\end{tabular}


Table 7. The corresponding GSI of maximum water supply amount for all reservoirs.

\begin{tabular}{ccccccccccc}
\hline Reliability & $\mathbf{0 . 9 7 5}$ & $\mathbf{0 . 9 5 0}$ & $\mathbf{0 . 9 2 5}$ & $\mathbf{2 0 . 9 0 0}$ & $\mathbf{2 0 . 8 7 5}$ & $\mathbf{\geq 0 . 8 5 0}$ & $\mathbf{\geq 0 . 8 2 5}$ & $\mathbf{\geq 0 . 8 0 0}$ & $\mathbf{\geq 0 . 7 7 5}$ & $\mathbf{\mathbf { 0 . 7 5 0 }}$ \\
\hline Feitsui & 0.28 & 0.68 & 1.09 & 1.45 & 1.90 & 2.50 & 3.08 & 3.73 & 4.49 & 5.17 \\
Shihmen & 0.25 & 0.70 & 1.13 & 1.85 & 2.51 & 3.16 & 3.83 & 4.57 & 5.56 & 6.52 \\
Bilin & 0.37 & 1.12 & 1.43 & 2.46 & 3.00 & 4.28 & 4.96 & 6.55 & 7.32 & 9.11 \\
Mingde & 0.30 & 0.66 & 0.96 & 1.42 & 2.06 & 2.80 & 3.66 & 4.54 & 5.47 & 6.35 \\
Tianhuahu & 0.31 & 0.59 & 1.00 & 1.54 & 2.27 & 3.13 & 3.59 & 4.60 & 5.71 & 6.87 \\
Liyutan & 0.33 & 0.72 & 1.09 & 1.72 & 2.25 & 2.96 & 3.67 & 4.47 & 5.34 & 6.31 \\
Jianming & 0.24 & 0.70 & 1.05 & 1.94 & 2.64 & 3.34 & 4.05 & 4.81 & 5.71 & 6.65 \\
Hushan & 0.52 & 0.83 & 1.33 & 1.81 & 2.37 & 3.03 & 4.10 & 4.85 & 6.06 & 6.95 \\
Nanhua & 0.58 & 1.03 & 1.65 & 2.08 & 2.51 & 3.18 & 3.81 & 4.65 & 5.56 & 6.85 \\
Mutan & 0.48 & 0.84 & 1.47 & 1.94 & 2.45 & 3.63 & 4.30 & 5.02 & 5.76 & 7.33 \\
\hline
\end{tabular}

\subsubsection{Preliminary Correlation Analysis Between WSR and GSI}

To examine the relationships between WSR and GSI, the linear regression method was employed to establish the evaluating function for each selected reservoir and study case. Since two of four selected parameters, namely the coefficient of variation of reservoir net inflow and the reservoir net inflow ratio of dry to wet seasons, were used to explain variations in the reservoir net inflow, and the statistical meaning of the coefficient of variation has better explanatory ability, so the linear regression evaluation employs the coefficient of variation of reservoir net inflow in advance. Three of the four selected parameters which are employed in advance to explain the relationships between WSRI and GSI are calculated and listed in Table 8. The structure of the linear regression function is established as follows:

$$
W S R I=C+v \cdot G S I+\omega \cdot C V_{I^{R}}+\xi \cdot K F+\psi \cdot W D T R
$$

where, $v, \omega, \xi$, and $\psi$ are the coefficients of GSI $C V_{I^{R}}, K F$, and WDTR respectively. The regression results of the selected case study are shown in Table 9. Owing to the fact that $C V_{I^{R}}, K F$, and WDTR were the fixed values for each selected case study, so the regression results that are shown in Table 9 could be treated as the characteristics of linear correlation between WSR and GSI for each case. Additionally, this study also integrates the variables from central Taiwan and all of Taiwan to establish the WSRI value estimation function, and the results are shown below:

$$
W S R I=C+v \cdot G S I+\omega \cdot C V_{I^{R}}+\xi \cdot K F+\psi \cdot W D T R
$$

Table 8. The interpretative parameters of the case studies' local conditions.

\begin{tabular}{ccccc}
\hline \multirow{2}{*}{ Reservoir } & \multicolumn{3}{c}{ Dimensionless Parameters } \\
\cline { 3 - 5 } & Feitsui & $\begin{array}{c}\text { Coefficient of } \\
\text { Variation }\end{array}$ & $\begin{array}{c}\text { Reservoir } \\
\text { Capacity Factor }\end{array}$ & $\begin{array}{c}\text { Time Ratio of Wet } \\
\text { and Dry Days }\end{array}$ \\
\hline \multirow{3}{*}{ Northern Taiwan } & Shihmen & 3.2181 & 0.4184 & 0.3651 \\
& Bilin & 2.9776 & 0.2985 & 0.2500 \\
& Mingde & 4.2930 & 0.3401 & 0.3332 \\
& Tianhuahu & 1.5219 & 0.1721 & 0.2144 \\
Central Taiwan & Liyutan & 1.2705 & 0.2959 & 0.3862 \\
& Jianming & 0.9423 & 0.2825 & 0.5494 \\
& Hushan & 1.4004 & 0.1664 & 0.6706 \\
& Nanhua & 3.7202 & 0.3623 & 0.4502 \\
& Mutan & 2.9547 & 0.4000 & 0.3696 \\
& Joint Operation & 1.1835 & 0.2611 & 0.1841 \\
& & 0.3968 & 0.5129 \\
\hline
\end{tabular}


Table 9. The estimated WSRI liner regression function of each reservoir.

\begin{tabular}{cccccccc}
\hline \multirow{2}{*}{ NO. } & \multirow{2}{*}{ Reservoir } & \multicolumn{5}{c}{ Coefficient of Regression Function } & \multirow{2}{*}{$\mathbf{R}^{\mathbf{2}}$} \\
\cline { 3 - 7 } & & $\boldsymbol{C}$ & $\boldsymbol{v}$ & $\boldsymbol{\omega}$ & $\boldsymbol{\xi}$ & $\boldsymbol{\psi}$ & \\
\hline 1 & Feitsui & 1.031 & -0.041 & 0.010 & -0.232 & 0.028 & 0.979 \\
2 & Shihmen & -3.803 & -0.034 & 0.319 & -4.836 & 19.894 & 0.993 \\
3 & Bilin & 0.868 & -0.026 & 0.185 & -0.532 & -0.809 & 0.953 \\
4 & Mingde & 0.766 & -0.035 & 0.139 & -0.667 & -1.333 & 0.968 \\
5 & Tianhuahu & 0.810 & -0.034 & 0.059 & -0.186 & 0.304 & 0.970 \\
6 & Liyutan & -0.969 & -0.306 & -0.112 & -2.063 & 4.847 & 0.980 \\
7 & Jianming & 0.879 & -0.035 & 0.807 & -5.914 & 0.469 & 0.991 \\
8 & Hushan & 0.845 & -0.034 & 0.151 & -1.034 & -0.747 & 0.971 \\
9 & Nanhua & 28.572 & -6.799 & 57.667 & -19.275 & -29.411 & 0.925 \\
10 & Mutan & 1.635 & -0.033 & 0.080 & -2.968 & 0.667 & 0.976 \\
11 & Joint Operation & 16.470 & -9.937 & 13.937 & -11.875 & -28.781 & 0.957 \\
\hline
\end{tabular}

The WSRI value estimation function for Central Taiwan:

$$
W S R I=0.950-0.035 \cdot G S I+0.006 \cdot C V_{I^{R}}-0.021 \cdot K F+0.020 \cdot W D T R, R^{2}=0.987
$$

The WSRI value estimation function for all of Taiwan:

$$
W S R I=0.960-0.032 \cdot G S I+0.001 \cdot C V_{I^{R}}-0.002 \cdot K F-0.004 \cdot W D T R, R^{2}=0.931
$$

3.2.3. Investigation of the Relationship Between WSRI and GSI in the Study Cases for Which the Official Planned Water Supply Amount is Known

In order to give this model significant empirical support at both the theoretical and applied levels, this study chose seven reservoirs from the ten selected reservoirs for which the water supply amount has been decided (the official planned water supply amount), and calculated the corresponding values of GSI and WSR, the results are listed with $K F, C V_{I^{R}}, D W I R$, and WDTR, in Table 10. It is assumed that the planned water supply amount of the seven selected reservoirs was derived after a round of professional evaluation. The WSRI and GSI estimation functions are as follows:

Table 10. The basic analytical data sets of seven selected reservoirs for which the planned water supply amount had been decided.

\begin{tabular}{ccccccc}
\hline & GSI & WSRI & $\begin{array}{c}\text { Net Inflow } \\
\text { Variation }\end{array}$ & $\begin{array}{c}\text { Reservoir } \\
\text { Capacity } \\
\text { Factor }\end{array}$ & $\begin{array}{c}\text { Time Ratio } \\
\text { of Wet to } \\
\text { Dry days }\end{array}$ & $\begin{array}{c}\text { Net Inflow } \\
\text { Ratio of Dry to } \\
\text { Wet Seasons }\end{array}$ \\
\hline Bilin & 1 & 0.968 & 2.978 & 0.340 & 0.333 & 0.410 \\
Hushan & 1.08 & 0.936 & 1.400 & 0.362 & 0.450 & 0.060 \\
Tianhuahu & 1.24 & 0.913 & 1.522 & 0.296 & 0.386 & 0.316 \\
Liyutan & 0.4 & 0.969 & 1.270 & 0.282 & 0.549 & 0.197 \\
Mingde & 1.37 & 0.902 & 4.293 & 0.172 & 0.214 & 0.566 \\
Jianming & 0.928 & 0.936 & 0.942 & 0.166 & 0.671 & 0.228 \\
Nanhua & 1.94 & 0.910 & 3.720 & 0.400 & 0.370 & 0.025 \\
\hline
\end{tabular}

The WSRI value estimation function:

$$
W S R I=0.887-0.067 \cdot G S I+0.014 \cdot C V_{I^{R}}+0.172 \cdot K F+0.093 \cdot W D T R, R^{2}=0.906
$$

The GSI value estimation function:

$$
G S I=11.449-12.935 \cdot W S R I+0.223 \cdot C V_{I^{R}}+2.424 \cdot K F+1.287 \cdot W D T R, R^{2}=0.940
$$


Though there is a high correlation between WSRI and GSI, the GSI cannot be made into an impersonal value; therefore the reasonable WSRI value estimation function should exclude the GSI in independent variables. For this reason, this study employs the WSRI value estimation function with $K F, C V_{I^{R}}$, and WDTR, as follows:

$$
W S R I=0.901-0.005 \cdot C V_{I^{R}}+0.071 \cdot K F+0.052 \cdot W D T R, R^{2}=0.268
$$

However, the result of Function (27) does not support these concerns, as the correlation coefficient only reaches 0.5 . Therefore, this study considers Function (27) with one more independent variable, parameter DWIR, as follows:

$$
W S R I=0.585+0.005 \cdot C V_{I^{R}}+0.457 \cdot K F+0.237 \cdot D W I R+0.334 \cdot W D T R, R^{2}=0.760
$$

The coefficient of correlation of the WSRI estimation function using $K F, C V_{I^{R}}, D W I R$, and WDTR reaches 0.87 . Because of the nature of $C V_{I^{R}}$ and $D W I R$, they are very close. In order to retrench the parameters in the estimation function, this study selects KF, DWIR, and WDTR to establish the WSRI value estimation function again. The results are as follows:

$$
W S R I=0.639+0.421 \cdot K F+0.220 \cdot D W I R+0.273 \cdot W D T R, R^{2}=0.739
$$

The $\mathrm{R}^{2}$ of Formula (29) can still reach 0.739 , and the coefficient of correlation is 0.86 . In order to survey the representation of Formula (29), the calibrated results are compared with the real values, as shown in Table 11.

Table 11. The calibration results of reasonable WSRI estimation function for seven selected reservoirs for which the planned water supply amount had been decided.

\begin{tabular}{cccc}
\hline Reservoir & Real Value & $\begin{array}{c}\text { Calibration } \\
\text { Value }\end{array}$ & Error Percentage (\%) \\
\hline Bilin & 0.968 & 0.964 & -0.450 \\
Hushan & 0.936 & 0.928 & -0.850 \\
Tianhuahu & 0.913 & 0.939 & 2.811 \\
Liyutan & 0.969 & 0.952 & -1.798 \\
Mingde & 0.902 & 0.895 & -0.824 \\
Jianming & 0.936 & 0.942 & 0.688 \\
Nanhua & 0.910 & 0.914 & 0.473 \\
\hline
\end{tabular}

\subsubsection{Validate the Estimation Ability of the Proposed Method}

In order to verify the estimated logic of the reasonable WSRI value estimation function, the estimation function is modeled with five of the seven selected reservoirs, with the remaining two reservoirs used as verification data. The results, which exclude the parameter value outside of the modeling data interval, are presented as follows, and the verification results are shown in Table 12.

Table 12. The verification results of reasonable WSRI estimation function.

\begin{tabular}{ccccc}
\hline Reservoir & Real Value & Calibration Value & Error Percentage (\%) & Formula No. \\
\hline Hushan & 0.936 & 0.928 & 0.860 & $(31)$ \\
Tianhuahu & 0.913 & 0.944 & -3.353 & $(31)$ \\
Tianhuahu & 0.913 & 0.941 & -3.106 & $(32)$ \\
Liyutan & 0.969 & 0.950 & 1.928 & $(32)$ \\
Hushan & 0.936 & 0.918 & 1.918 & $(33)$ \\
Liyutan & 0.969 & 0.941 & 2.837 & $(33)$ \\
\hline
\end{tabular}


For Hushan and Tianhuahu reservoirs:

$$
W S R I=0.612+0.468 \cdot K F+0.256 \cdot D W I R+0.292 \cdot W D T R, R^{2}=0.923
$$

For Tianhuahu and Liyutan reservoirs:

$$
W S R I=0.643+0.434 \cdot K F+0.229 \cdot D W I R+0.254 \cdot W D T R, R^{2}=0.962
$$

For Hushan and Liyutan reservoirs:

$$
W S R I=0.654+0.391 \cdot K F+0.222 \cdot D W I R+0.242 \cdot W D T R, R^{2}=0.812
$$

\section{Discussion}

\subsection{Results}

\subsubsection{The Main Analytical Index of this Study}

The water supply analysis was conducted with daily data, and the purpose of the water supply was to meet the given water supply amount, therefore, the performance for both the time and volumetric reliabilities were very close, and the results are shown in Tables 4 and 5. Considering the convenience of the actual operation, volumetric reliability was adopted as the main analytical index.

\subsubsection{The Characteristic of the Case Studies' Local Conditions}

Two points are worth noting in Table 8. The first is the values of the reservoir characteristic parameters. Since the off-stream reservoirs were subjected to the transbasin diversion capacity, except the Nanhua reservoir, which had a level of instream water that was higher than the others, the coefficients of variation were less than those of the on-stream reservoirs. For the same reason, since the inflow temporal distribution of the off-stream reservoirs was more stable than that of the on-stream reservoirs, the performances on the time ratio of wet to dry days for the off-stream reservoirs were greater than those of the on-stream ones. The time ratio of wet to dry days also indicates that the reservoir inflow temporal distribution in Northern Taiwan is more uniform than in Southern Taiwan. Second, regarding the reservoir capacity factors, the effective capacity of Feitsui reservoir is 24.3 times that of Mingde reservoir, while and the reservoir capacity factor of the former is only 2.43 times that of the latter. Additionally, the reservoir capacity factor of Mingde reservoir is greater than that of Feitsui reservoir. Clearly, the reservoir capacity factor is an indicator of reservoir regulation ability.

\subsubsection{The Water Supply Reliability of GSI}

The SI/GSI considers the socioeconomic impact of water shortage events in the definitions as an indicator of water supply planning. Though the consideration of SI = 1 is the conceptual ideal condition with a $10 \%$ annual shortage rate occurring once every year; this consideration cannot serve as the general criterion in different local conditions of planning site. This is because the consideration of socioeconomic impact does not appear to agree with managers' judgment when the latter uses the given design to regulate the variance of streamflow for the given demand. From the estimated results that shown in the Table 6 it can be seen that although the corresponding water supply reliability values of GSI $=1$ in selected study cases are above 0.9 , the final scheme of reservoir planning was not decided with the strict criterion that GSI $=1$ (see Table 10). Looking again at Table 10, although the final scheme of water supply planning has different GSI values, the water supply reliability is always above 0.9. These results imply that the managers' judgments for reservoirs' capacity design depend on specific opinions, and that these would not be considered as part of the socioeconomic impact that is defined in the definition of GSI/SI. 


\subsubsection{The Relationship Between the WSRI and GSI}

The results in Table 9 indicate that WSRI and GSI were strongly correlated. In that part of the linear regression function, the $R^{2}$ was between 0.925 and $\sim 0.993$. Although the $R^{2}$ of each reservoir's linear regression function performed well, the parameters of the regression were without consistent coefficient characteristics, with positive or negative signs, with regard to the four variables and the constant. Therefore, the data on all and only Central Taiwan's reservoirs were collected in order to run separate regression analyses on them, and the results are shown in Formulae (23) and (24). The results showed that the WSRI was closely connected to the GSI, and that the WSRI was moderately and negatively related to GSI (The definition of SI is dependent on the deficit rate, and the definition of WSRI is dependent on the sufficient rate).

4.1.5. Relationship Evaluation Between the Corresponding WSRI and GSI Values of Official Planned Water Supply Amount

Formula (29), which models seven selected reservoirs with planned water supply amounts, indicates that the WSRI was significantly and positively associated with the reservoir capacity factor, the time ratio of wet to dry days, WDTR, and the reservoir net inflow ratio of dry to wet seasons, DWIR. In addition, the combination of WDTR and DWIR may provide more effective information to explain the variance of streamflow than the coefficient of variation $C V_{I^{R}}$ for WSRI estimation in Taiwan. In this case the formula indicated a high correlation coefficient of 0.86 , and the verification results performed well, as shown in Table 11. The results in Table 12 were also positive.

\subsection{Extended Discussions}

As water requirements and ecological consciousness increase, so does demand for more precisely controlled and predictive water resources development growth. Form the viewpoint of the public who use the water supply, it is necessary for the government to provide a transparent bottom-up explanation for its water supply policy and the necessity of developing water resources. Clearly, despite the SI served the consideration of socioeconomic impact to consider the effect of water shortages on water users in its definition, water resource managers are does not follow any specific consideration of socioeconomic impact to judge the schemes of reservoirs when they facing different combinations of water shortages' intensity and frequency, thus the SI value would not be a good explanation for water supply policy and the necessity of developing water resources with regard to public. For this reason, this study provides an approach to translate the SI value into water supply reliability, which is easier to understand. For any given water supply system, the estimated results of this study could serve as an additional remark on different SI values to explain their water supply considerations. For a new planning site, the estimated results of this study could provide another way for engineers and managers to evaluate the maximum water supply ability and its corresponding SI value to serve as the initial consideration of water supply system planning.

\section{Conclusions and Suggestions}

\subsection{Conclusions}

This study defined three dimensionless parameters, as follows: the reservoir capacity factor, $K F$, which represents the regulatory ability of the reservoir; the net inflow ratio of dry to wet seasons, $D W I R$, which represents the variation in the degree of inflow; and the time ratio of wet to dry days, WDTR, which represents the proportion of the distribution of the large inflow discharge and small inflow discharge. These three dimensionless parameters are used to explain different elements of each reservoir, including the capacity scale, location, on-stream/off-stream operation type, and single or joint operation. In addition, the combination of WDTR and DWIR may provide more effective information to explain the variance of streamflow than the coefficient of variation $C V_{I^{R}}$ for WSRI estimation in Taiwan. 
From the analysis of the results for each reservoir, and the integration of those for all the reservoirs, a high correlation between the WSRI and GSI was found. In both pure water resources operation and complex water resources facilities operation (e.g., joint operation of reservoirs), the uncertainty caused by the spatial and temporal distribution of rainfall in the operation of water resource system shall be presented to decision makers or to the general public in the most comprehensible way. When the reservoir capacity of an existing reservoir is reduced due to reservoir sedimentation, the analysis parameters proposed in this study may be applied to obtaining the WSRI value, which facilitates the explanation of water supply difficulty.

The seven selected reservoirs which official planned water supply amounts has been know had a GSI value interval that varied from 0.4 to 1.94 and the corresponding WSRI value interval varied from 0.968 to 0.902 . Although the consideration of SI $=1$ was considered as the conceptual ideal initial condition, i.e., that the $10 \%$ annual shortage rate occurs once every year, but the final schemes of reservoir planning were result in different GSI values, and their water supply reliabilities were all above 0.9. These results imply that the managers' judgment for reservoirs' capacity design were dependent on specific opinions, which did not follow the conceptual ideal consideration of the socioeconomic impact in GSI/SI. In addition, the definition of WSRI is clearer and easier to understand than that of GSI, and thus adopting the former as a substitute for the latter as a planning index is worth further exploration.

Through the calibration and verification procedure, assuming that the official planned water supply amount of the seven selected reservoirs went through a round of professional evaluation, the correlation coefficients of WSRI calculations and estimations were all above 0.8. The results demonstrate that WSRI can be practically implemented and can provide adequate results. For any given water supply system, the estimated results of this study could serve as an additional remark on different SI values to explain their water supply considerations. For a new planning site, the reasonable water supply reliability function could provide another way for engineers and managers to evaluate the maximum water supply ability, and then calculate its corresponding SI value to serve as the initial consideration of water supply system planning.

In Taiwan, from the comparison with the interval of WSRI of seven reservoirs, the standard interval of WI that the of Taiwan Water Corporation uses, and the water supply priorities right of different kinds of demand in Taiwan, it is suggested that the reservoirs that are expected to supply only public water adopt the WSRI as the water supply index with 0.9 (the middle value of the moderate deficit level of the WI) for the lower bound, and 0.975 (the middle value of the normal level of the WI) as the upper bound. Reservoirs that are expected to supply only agricultural water demand have more flexibility than those for public water-use. Therefore, it is suggested that the WSRI restrictions are relaxed by 0.025 , and that the values 0.95 and 0.875 be used as the upper and the lower bounds, respectively. Reservoirs that are only expected to meet industrial water demand have less flexibility than those for public water-use. Therefore, it is suggested that the WSRI reduces its restrictions by 0.025 , and uses the values 1.0 and the 0.925 as the upper and the lower bounds, respectively. These suggested value relaxations and reductions could be undertaken for further exploration of the assumptions underlying this study.

The "expected levels of supply" form the socioeconomic part of the definition [30]. The standard of water supply reliability would be related to water pricing for each kind of demand in the more advanced water supply system organization (such as the rule curve, regional regulation policy, and so on.), if the standards of water supply and water pricing for each kind of demand could be established, it would be helpful to developing an efficient and transparent bottom-up approach and involving all stakeholders for water resource management and development.

The sets of water requirement and corresponding tolerable water shortage for each purpose of a multipurpose reservoir shall be compiled as one synthetic value set as reservoir's overall water-shortage tolerance. Such statistics may serve as references for the operation of a multipurpose reservoir. 


\subsection{Suggestions}

Since the WSRI is an expression of the average water supply potential, water users or managers may want to know the frequency and intensity of potential water shortages that caused by hydrologic conditions, water quality conditions, and water supply or water distribution system component failures [31-34] they may have to face one day, or they may want to take action to avoid a specific potential crisis of water shortage. Hence, an interesting avenue of investigation in future research would be the incorporation of the WSRI with the concepts contained in ALARP (as low as reasonably practicable) [35], as shown in Figure 7. The width of the inverted triangle can be seen as the intensity of a water shortage event, and the height can be seen as the frequency. From top to bottom the inverted triangle represents low to high frequency. The ALARP region between frequency and intensity is illustrated in Figure 8. The ALAPR could be performed with a questionnaire based on each kind of demand through the mechanism of reasonable water price response (high reliability cost high price) [36]. It could serve to provide general principles for management in organizing a suitable water supply system for each kind of water use, and also in their preparation of a backup system for the water supply target.

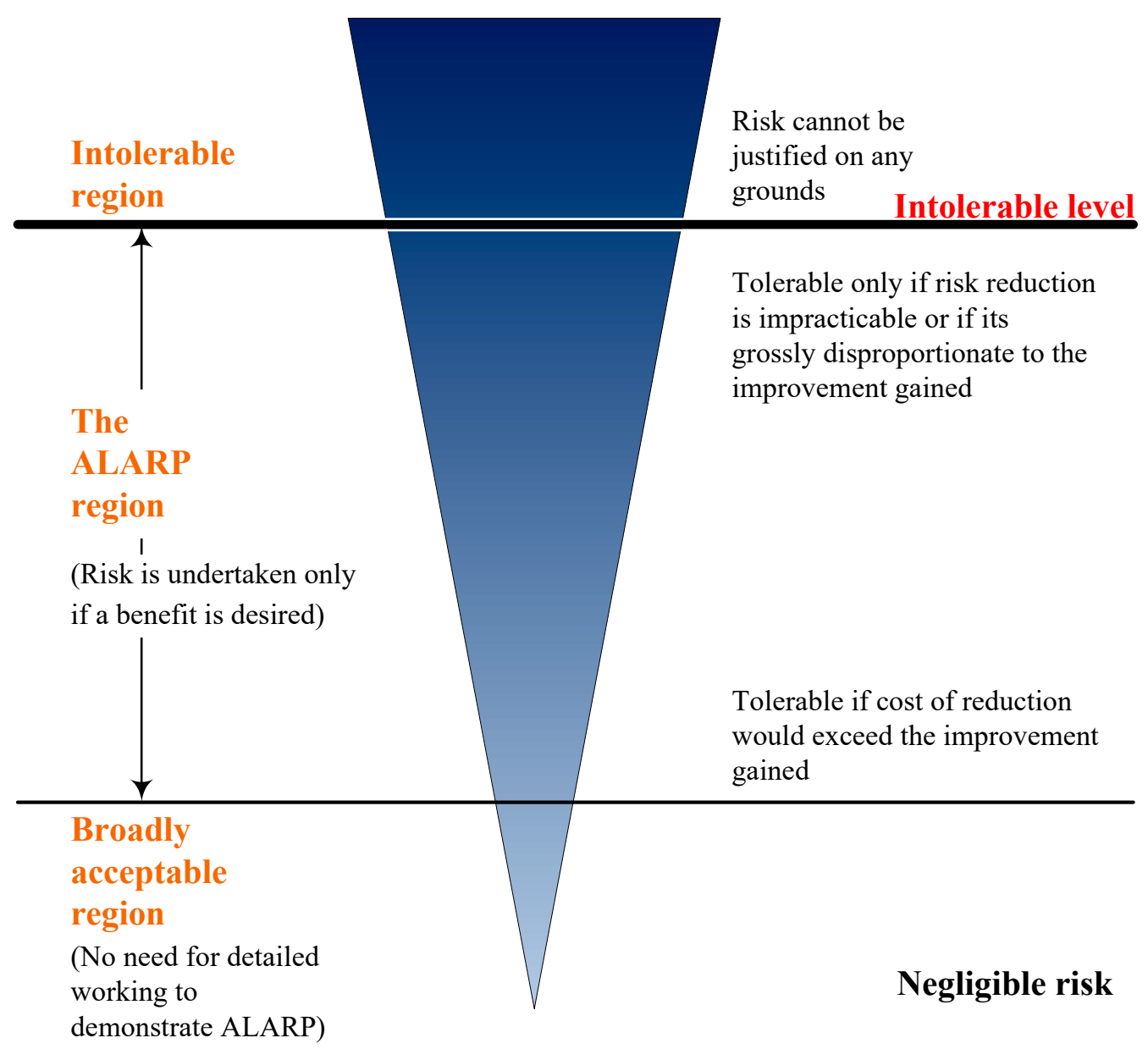

Figure 7. Levels of risk and ALARP $[35,37]$. 


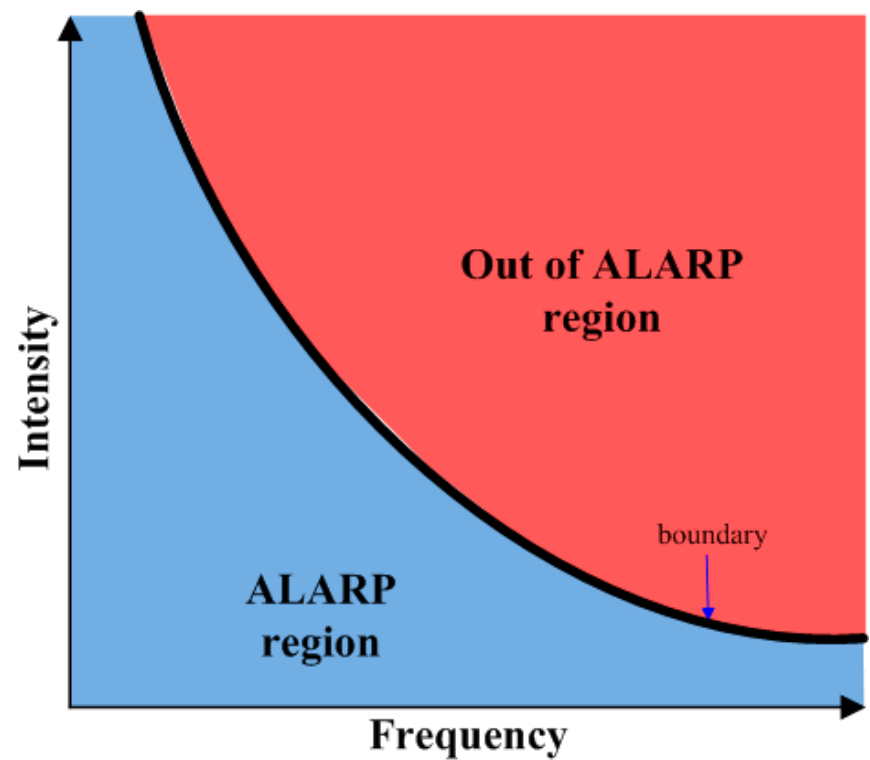

Figure 8. The ALARP region between frequency and magnitude.

Author Contributions: B.P.-T.C. and C.-S.C. conceived of the presented idea. B.P.-T.C. developed the theory and performed the computations.

Funding: This research was funded by Contract PG9105-0154 from the Water Resources Agency, Taiwan.

Acknowledgments: This research was funded by Contract PG9105-0154 from the Water Resources Agency, Taiwan.

Conflicts of Interest: The authors declare no conflict of interest.

\section{References}

1. Ghosh, S.; Mujumdar, P.P. Nonparametric methods for modeling GCM and scenario uncertainty in drought assessment. Water Resour. Res. 2007, 43, W07405. [CrossRef]

2. Kiem, A.S.; Franks, S.W. Elevated drought risk due to multi-decadal climate variability. In Water Resources Systems-Hydrological Risk, Management and Development; Blöschl, G., Franks, S., Kumagai, M., Musiake, K., Rosbjerg, D., Eds.; IAHS Press, Centre for Ecology and Hydrology, Wallingford: Oxfordshire, UK, 2003; pp. 165-172.

3. O'Hara, J.; Georgakakos, K. Quantifying the urban water supply impacts of climate change. Water Resour. Manag. 2008, 22, 1477-1497. [CrossRef]

4. Dai, A.; Qian, T.; Trenberth, K.E.; Milliman, J.D. Changes in continental freshwater discharge from 1948 to 2004. J. Clim. 2009, 22, 2773-2792. [CrossRef]

5. Al-katheeri, E. Towards the establishment of water management in Abu Dhabi Emirate. Water Resour. Manag. 2008, 22, 205-215. [CrossRef]

6. Mukheibir, P. Water resources management strategies for adaptation to climate-induced impacts in South Africa. Water Resour. Manag. 2008, 22, 1259-1276. [CrossRef]

7. Kallis, G. Droughts. Ann. Rev. Environ. Resour. 2008, 33, 85-118. [CrossRef]

8. Water Resources Agency. Statistics of Water Resources; WRA: Taipei, Taiwan, 2008.

9. Water Resources Agency. Water Resources News; WRA: Taipei, Taiwan, 2009. Available online: http: //www.wra.gov.tw/ (accessed on 30 December 2009).

10. Water Resources Agency. Land Subsidence Prevention and Reclamation Data Network; WRA: Taipei, Taiwan, 2009. Available online: http://www.water.tku.edu.tw/sub91/index_home.aspx (accessed on 30 December 2009).

11. Council for Economic Planning and Development. National Land Restoration Strategic Program and Action Plan; Department of Executive: Taipei, Taiwan, 2006.

12. International Institute for Sustainable Development. A Summary Report of the 4th World Water Forum. World Water Forum Bull. 2006, 82. Available online: http://www.iisd.ca/YMB/WORLDWATER4/ (accessed on 30 December 2009). 
13. Takeuchi, K. Chance-constrained model for real-time reservoir operation using drought duration curve. Water Resour. Res. 1986, 22, 551-558. [CrossRef]

14. Water Resources Agency. Defining the Drought Indicators for Central and Sourthern Taiwan Areas; WRA: Taipei, Taiwan, 1999.

15. Thompson, S.A. Hydrology for Water Management; A.A. Balkema: Rotterdam, The Netherlands; Brookfield, VT, USA, 1999.

16. Hydrologic Engineering Center. Hydrologic Engineering Methods for Water Resources Development; U.S. Army Corps of Engineers: Davis, CA, USA, 1975.

17. Hwang, J.S. An Appraisal of reservoir planning and shortage tolerances in Taiwan. In Proceedings of the Third Conference on Hydraulic Engineering, Taipei, Taiwan, 30-31 May 1986; pp. 51-64.

18. Japan Water Resources Development Public Corp. Drought Assessment; Mizu To Tomoni 159: Tokyo, Japan, 1977; p. 8.

19. Hsu, S.K. Shortage indices for water-resources planning in Taiwan. J. Water Resour. Plan. Manag. 1995, 121, 119-131. [CrossRef]

20. Chang, F.J.; Lai, J.S.; Kao, L.S. Optimization of operation rule curves and flushing schedule in a reservoir. Hydrol. Process. 2003, 17, 1623-1640. [CrossRef]

21. Hsu, N.S.; Cheng, W.C.; Cheng, W.M.; Wei, C.C.; Yeh, W.W.G. Optimization and capacity expansion of a water distribution system. Adv. Water Resour. 2008, 31, 776-786. [CrossRef]

22. Tung, C.P.; Hsu, S.Y.; Liu, C.M.; Li, J.S. Application of the genetic algorithm for optimizing operation rules of the LiYuTan reservoir in Taiwan. J. Am. Water Resour. Assoc. 2003, 39, 649-657. [CrossRef]

23. Gippel, C.J.; Stewardson, M.J. Use of wetted perimeter in defining minimum environmental flows. Regul. Rivers Res. Manag. 1998, 14, 53-67. [CrossRef]

24. Jowett, I.G. Instream flow methods: A comparison of approaches. Regul. Rivers Res. Manag. 1997, 13, 115-127. [CrossRef]

25. MacDonnell, L.J. Return to the river: Environmental flow policy in the United States and Canada. J. Am. Water Resour. Assoc. 2009, 45, 1087-1099. [CrossRef]

26. Linsley, R.K.; Franzini, J.B. Water-Resources Engineering, 3rd ed.; McGraw-Hill: New York, NY, USA, 1979.

27. Water Resources Agency. Consuming Water Statistic Database; WRA: Taipei, Taiwan, 2019. Available online: http://wuss.wra.gov.tw/systeminfo.aspx (accessed on 16 September 2019).

28. Cabrera, E.; Cobacho, R.; Lund, J.R. Regional Water System Management: Water Conservation, Water Supply and System Integration; A.A. Balkema: Lisse, The Netherlands, 2002.

29. McMahon, T.A.; Vogel, R.M.; Pegram, G.G.S.; Peel, M.C.; Etkin, D. Global streamflows-part 2: Reservoir storage-yield performance. J. Hydrol. 2007, 347, 260-271. [CrossRef]

30. Grigg, N.S. Water Resources Management: Principles, Regulations, and Cases; McGraw-Hill: New York, NY, USA, 1996.

31. Tchorzewska-Cieslak, B. Estimating the acceptance of bearing the cost of the risks associated with the management of water supply system. Ochr. Śr. 2007, 29, 69-72.

32. Pietrucha-Urbanik, K. Failure Prediction in Water Supply System-Current Issues. In Theory and Engineering of Complex Systems and Dependability; Advances in Intelligent Systems and Computing; Zamojski, W., Mazurkiewicz, J., Sugier, J., Walkowiak, T., Kacprzyk, J., Eds.; Springer International Publishing: Cham, Switzerland, 2015; Volume 365, pp. 351-358.

33. Rak, J.; Pietrucha-Urbanik, K. An Approach to Determine Risk Indices for Drinking Water-Study Investigation. Sustainability 2019, 11, 3189. [CrossRef]

34. Tchórzewska-Cieślak, B. Bayesian model of urban water safety management. Glob. Nest J. 2014, 16, 667-675.

35. Evans, A.W. Evaluating public transport and road safety measures. Accid. Anal. Prev. 1994, 26, 411-428. [CrossRef]

36. Sun, G.; McNulty, S.G.; Myers, J.A.M.; Cohen, E.C. Impacts of multiple stresses on water demand and supply across the Southeastern United States. J. Am. Water Resour. Assoc. 2008, 44, 1441-1457. [CrossRef]

37. Health and Safety Executive. The Tolerability of Risk from Nuclear Power Stations; HMSO: London, UK, 1988.

(C) 2019 by the authors. Licensee MDPI, Basel, Switzerland. This article is an open access article distributed under the terms and conditions of the Creative Commons Attribution (CC BY) license (http://creativecommons.org/licenses/by/4.0/). 